\title{
Physical Methods for the Preparation of Hybrid Nanocomposite Polymer Latex Particles
}

\author{
Roberto F.A. Teixeira and Stefan A.F. Bon
}

\begin{abstract}
In this chapter, we will highlight conceptual physical approaches towards the fabrication of nanocomposite polymer latexes in which each individual latex particle contains one or more "hard" nanoparticles, such as clays, silicates, titanates, or other metal(oxides). By "physical approaches" we mean that the "hard" nanoparticles are added as pre-existing entities, and are not synthesized in situ as part of the nanocomposite polymer latex fabrication process. We will narrow our discussion to focus on physical methods that rely on the assembly of nanoparticles onto the latex particles after the latex particles have been formed, or its reciprocal analogue, the adhesion of polymer onto an inorganic nanoparticle. First, will discuss the phenomenon of heterocoagulation and its various driving forces, such as electrostatic interactions, the hydrophobic effect, and secondary molecular interactions. We will then address methods that involve assembly of nanoparticles onto or around the more liquid precursors (i.e., swollen/growing latex particles or monomer droplets). We will focus on the phenomenon of Pickering stabilization. We will then discuss features of particle interaction with soft interfaces, and see how the adhesion of particles onto emulsion droplets can be applied in suspension, miniemulsion, and emulsion polymerization. Finally, we will very briefly mention some interesting methods that make use of interface-driven templating for making well-defined assembled clusters and supracolloidal structures.
\end{abstract}

Keywords Colloids · Heterocoagulation · Nanocomposites · Pickering stabilization $\cdot$ Polymer latex $\cdot$ Self-assembly $\cdot$ Supracolloidal structures

S.A.F. Bon (訩 and R.F.A. Teixeira

Department of Chemistry, University of Warwick, Coventry CV4 7AL, UK

e-mail: S.Bon@warwick.ac.uk; R.F.Teixeira@warwick.ac.uk 


\section{Contents}

1 Assembly of Nanoparticles onto Prefabricated "Larger" Particles via Heterocoagulation . 20

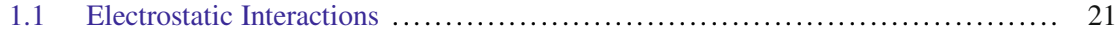

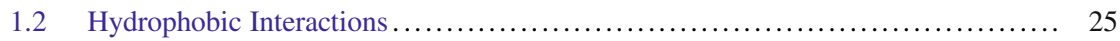

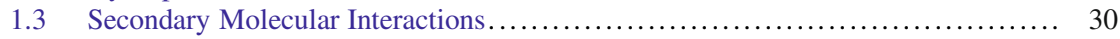

2 Assembly of Nanoparticles onto Prefabricated Larger Particles via Repetitive

Heterocoagulation: the Layer-by-Layer Technique $\ldots \ldots \ldots \ldots \ldots \ldots \ldots \ldots \ldots \ldots \ldots \ldots . \ldots \ldots$

3 Assembly of Nanoparticles onto Emulsion Monomer Droplets

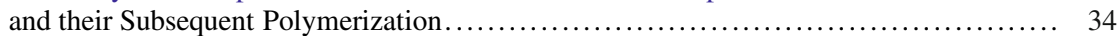

3.1 Pickering Stabilization: Adhesion of Particles to "Soft" Interfaces ............. 34

3.2 Polymerization of Emulsion Droplets Armored with Inorganic

Nanoparticles: Pickering Suspension and Miniemulsion

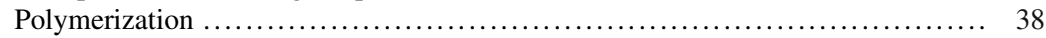

4 Assembly of Nanoparticles onto the Surface of Polymer Colloids Throughout

Emulsion Polymerization: Solids-Stabilized, or Pickering, Emulsion Polymerization .... 42

5 Hybrid Polymer Colloids Through Assembly of Colloidal Building Blocks

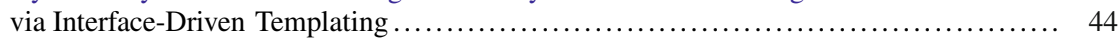

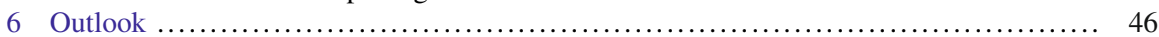

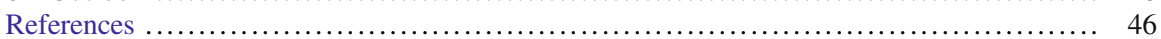

\section{Assembly of Nanoparticles onto Prefabricated "Larger" Particles via Heterocoagulation}

Heterocoagulation is the mutual adhesion of particles of a dissimilar nature upon collision, as a result of their individual Brownian motion. Brownian motion is a stochastic, or random, movement of colloidal particles suspended in a fluid (or gas) as a result of the internal thermal energy of the system, and thus of collisions with the solvent (or gas) molecules, as pointed out independently by Einstein and Smoluchowski. Derjaguin pointed out that the term "heteroadagulation" should be used for adhesion of small particles that move through Brownian motion onto much larger objects, whose Brownian motion can be neglected, such as fibers [1]. For example, Jachowicz and Berthiaume [2] reported the deposition of cationic, anionic, and neutral silicon oil droplets in the form of oil-in-water emulsions on native or cationically modified human hair fibers, driven by electrostatic forces.

Since heterocoagulation is a stochastic process, great care needs to be taken not to end up with large fractal clusters or flocks of the two colloidal components. Driving forces to promote adhesion of inorganic nanoparticles onto the surface of polymer latex particles, or vice versa, can be based on a variety of forces, such as electrostatic attraction, hydrophobic interactions, and secondary molecular interactions such as (multiple) hydrogen bond interactions and specific molecular recognition (e.g. complementary proteins like avidin-biotin). 


\subsection{Electrostatic Interactions}

When an inorganic nanoparticle has the opposite charge to a larger polymer latex particle, they will attract each other on the basis of Coulomb's law. The range in which this attractive force is felt depends on the charge densities and, more importantly, on the extent of the diffuse double layers of the two interacting colloids. If one wants to adhere more than one nanoparticle onto a polymer latex sphere, the small particles already present on the surface of the latex particle will influence the adsorption behavior of the next-to-be-adsorbed nanoparticle. The spatial distribution for sorption of the nanoparticles on the surface is logically influenced, and a close encounter can even locally be of a repulsive nature. This charge inversion is also the reason why typically only a single layer of nanoparticles can adhere onto the surface of the central particle.

The attraction between oppositely charged colloids can be understood and modeled using the DLVO theory [3-6]. The DLVO theory links the van der Waals attraction between particles with the electrostatic effects resulting from the presence of a double layer of counterions. A detailed theoretical discussion lies outside the scope of this chapter. One of the difficulties of the DLVO theory is that an exact analytical description of interaction of overlapping double layers is only known for flat, infinite parallel surfaces. For spherical double layers, approximations need to be made or numerical theoretical simulations need to be performed.

Hogg, Healy, and Fuerstenau [7] developed their HHF theory to describe the interactions of two particles of different size. In 1985, Matijevi and Barouch [8] evaluated the validity of the HHF theory for the electrostatic interaction between two surfaces of different sizes for both unlike particles with potentials opposite in sign, and for particles with same sign potentials. The computational calculations overcame the problem of the accuracy in the evaluation of incomplete elliptic integrals of the first kind, which is a direct consequence of a non-linearity of the PoissonBoltzmann equation. They concluded that for systems with dissimilar particles with either opposite signs or the same sign, the approximation of the HHF theory achieved good results. However, when potential differences increased, marked deviations from the HHF theory were found.

In 1976, Bleier and Matijevic [9] reported the interaction, in aqueous solution, of two different monodisperse hydrous chromium(III) oxide sols of approximate radii of 110 and $186 \mathrm{~nm}$ with poly(vinyl chloride) latexes of ca. 169 and $255 \mathrm{~nm}$ in radius and of relatively narrow particle size distribution. Zeta-potential measurements of the chromium(III) oxide sols as a function of $\mathrm{pH}$ in a $8.9 \mathrm{mM}$ background electrolyte solution of $\mathrm{NaNO}_{3}$ showed an isoelectric point (IEP) of pH 7.2-7.6. Below the IEP, the sols were positively charged and negatively charged above the IEP. Dispersions of the inorganic sols were stable below $\mathrm{pH} 4.6$ and above $\mathrm{pH}$ 9.0. Both PVC latexes were stable and negatively charged throughout the $\mathrm{pH}$ range (3.0-11.0) investigated. They found that rapid coagulation of mixtures of the inorganic sol with the polymer latex occurred between $\mathrm{pH} 3.0$ and 4.6. Because both individual dispersions were stable, this was therefore directly ascribed to mutual coagulation of 
oppositely charged particles. These experimental observations were in agreement with the earlier predictions by the HHF theory [7]. Obviously, bulk coagulation needs to be avoided. A logical parameter therefore is the geometric ratio of the sizes of the two different colloids involved: the larger the size, the easier it would be to avoid mass coagulation. Note that Vincent et al. [10-12] showed that small particles, in the presence of a low electrolyte concentration, can act as bridging flocculants of large particles of opposite charge.

Vincent and coworkers described the adsorption-desorption behavior of small positively charged polystyrene latex particles onto much larger negatively charged polystyrene spheres $[13,14]$. In addition to surface charges, both sets of particles had a layer of adsorbed poly(vinyl alcohol) so that the influence of the extent of the diffuse double layer upon variation of the electrolyte concentration could be investigated. At low electrolyte concentration, the diffuse double layers are extended and the small particles adhere in a way that shows a relatively large spatial distance between them on the surface of the large sphere. The extended double layers effectively cause a strong and irreversible adsorption. The lateral repulsion force and the electrostatic adsorption force both decrease when the electrolyte concentration is increased. The spatial arrangement of the small particles may now experience a lateral net attractive rather than repulsive force, which leads to clustering of the nanoparticles on the surface. The adsorption behavior also can become reversible, being a direct function of the thickness of the sterically stabilizing poly(vinyl alcohol) layers around both the small particles and the larger latex spheres, and of the volume fractions of the particles in the system.

Hansen and Matijević [15] studied the adsorption of negatively charged (carboxylic acid functionality) poly(methyl methacrylate) (PMMA) latex of average particle radius of $40 \mathrm{~nm}$ onto to much larger positive inorganic sols made from either hydrated aluminum oxide (particle radius $250 \mathrm{~nm}$ ) or hematite (radius 272-276 nm). The polymer latex showed an IEP of $\mathrm{pH} 3.8$, the hydrated aluminum hydroxide particles an IEP of $\mathrm{pH} \mathrm{8.7,} \mathrm{and} \mathrm{the} \mathrm{hematite} \mathrm{had} \mathrm{a} \mathrm{value} \mathrm{of} \mathrm{pH} 7.2$, all measured in $0.01 \mathrm{M} \mathrm{KNO}_{3}$ background electrolyte. Above the IEPs of these dispersions, the latex and the solids were negatively charged. The adsorption process of the smaller latex particles proceeded in a reversible manner, implying equilibrium conditions. The maximum number of small particles adsorbed onto a large particle was shown to increase with increasing $\mathrm{KNO}_{3}$ concentration, reaching practically a "fully covered" monolayer. This is in agreement with the findings by Vincent [13, 14]. It was possible to compare the interactions energies obtained from the adsorption isotherm of the latex poly(methyl methacrylate $c o$-methacrylic acid) onto positive oxide (alumina or hematite) to the calculated values according to the derived expression based on the two-dimensional Poisson-Boltzmann equation [16].

Furusawa and Anzai investigated the heterocoagulation of a highly monodisperse amphoteric polymer latex (particle diameter $250 \mathrm{~nm}$, IEP ca. pH 6.8 in $5.0 \mathrm{mM} \mathrm{KCl}$ background electrolyte, positively charged at low $\mathrm{pH}$ ) onto various silica spheres (diameters 240, 460, 960, and $1590 \mathrm{~nm}$; IEP ca. $\mathrm{pH}$ 3.0) dispersed in pure water or upon addition of various hydroxypropyl celluloses (HPCs) [17, 18]. Stable dispersions for both individual particles under the condition that they had opposite 

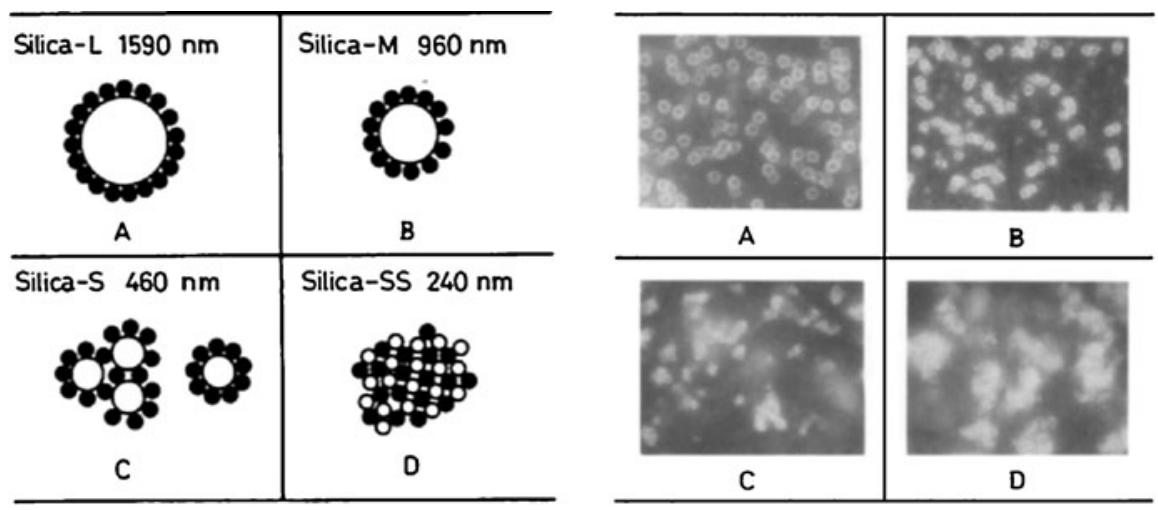

Fig. 1 Left: (a-d) Different morphologies of heterocoagulate particles that can be obtained when the relative sizes of the two colloids are varied. Right: Micrographs obtained from heterocoagulation of an amphoteric latex (diameter $250 \mathrm{~nm}$ ) at $\mathrm{pH} 5.6$, at which it has a cationic surface charge, with negatively charged silica particles of various diameters: 1590 (a), 960 (b), 460 (c), and 240 (d) nm. Reproduced from Figs. 2 and 3 from [17]
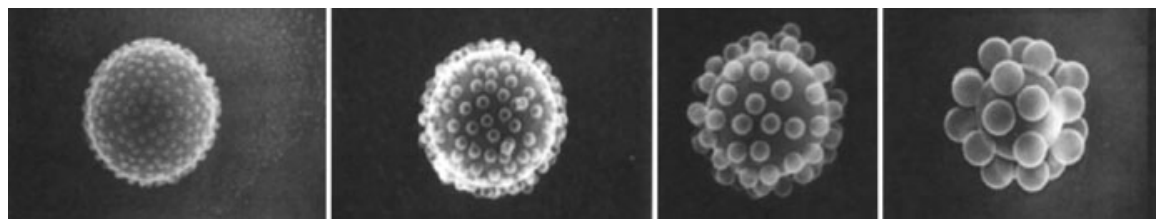

Fig. 2 TFFDSEM images of various anionic polymer latexes of different sizes. From left to right: poly(vinylidene chloride) latex of $116 \mathrm{~nm}$, and polystyrene particles of 180,320, and $696 \mathrm{~nm}$ in diameter, assembled onto a large cationic polystyrene latex of $2170 \mathrm{~nm}$ via heterocoagulation in $0.5 \mathrm{mM} \mathrm{KCl}$ background electrolyte. Images reproduced from Fig. 7 from [20]

surface charge only occurred in the narrow $\mathrm{pH}$ window between $\mathrm{pH} 5$ and 6 . Stable raspberry-like heterocoagulates were obtained when the ratio of the diameter of the silica to latex particle was greater than 3 . For ratios of a lower value, larger irregular aggregates were obtained (see Fig. 1).

Harley, Thomson, and Vincent used thin-film freeze-drying scanning electron microscope (TFFDSEM) [19] as a visualization method to study the heterocoagulation of monodisperse anionic polymer latexes of various diameters made using potassium persulfate as initiator (i.e., polystyrene spheres of 696, 320, and $180 \mathrm{~nm}$ and a poly(vinylidene chloride) latex of $116 \mathrm{~nm}$ ) onto a large cationic polystyrene latex of $2170 \mathrm{~nm}$ in diameter, using azobis(isobutylamidine)dihydrochloride as initiator [20]. Adsorption isotherms of the four sets of negatively charged particles onto the large cationic microspheres were of the "high-affinity" type, in $0.5 \mathrm{mM} \mathrm{KCl}$ background electrolyte. This was logical and ascribed directly to extended interacting double layers. The particles packed beautifully symmetrically onto the surface (see Fig. 2), implying that lateral electrostatic repulsion between neighboring adhered particles plays a key role. 

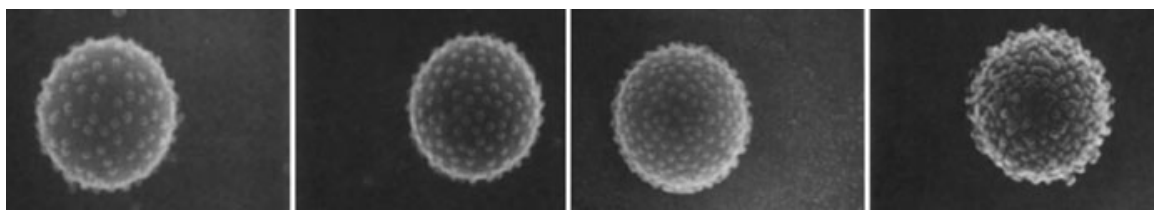

Fig. 3 TFFDSEM images of an anionic poly(vinylidene chloride) latex of $116 \mathrm{~nm}$, assembled onto a large cationic polystyrene latex of $2170 \mathrm{~nm}$ via heterocoagulation at various background electrolyte concentrations of $\mathrm{KCl}$ : from left to right, $0.01,0.1,0.5$, and $5.0 \mathrm{mM}$. Images reproduced from Fig. 9 from [20]

The influence of the concentration of the background electrolyte was beautifully captured in a series of images using the anionic poly(vinylidene chloride) latex of $116 \mathrm{~nm}$, at $\mathrm{KCl}$ concentrations of $0.01,0.1,0.5$, and $5.0 \mathrm{mM}$ (see Fig. 3). Increasing the background electrolyte concentration and thus effectively reducing the thickness of the double layer led to closer spatial arrangements of the particles onto the surface of the central microsphere. At the highest electrolyte concentration, one could even argue the onset of an attractive rather than repulsive force between neighboring particles.

Ottewill and coworkers used hetercoagulation as a route to hard core/soft shell polymer composites. Small cationic latex particles of poly(butyl methacrylate) were adhered onto the surface of larger anionic polystyrene latex particles [21]. Upon raising the temperature of the assembled colloidal dispersion, the poly(butyl methacrylate) latex particles underwent film formation leading to a smooth shell. Okubo examined the reciprocal concept of using heterocoagulation as a method for preparation of soft core/hard shell polymer composites. The source for hard particles, however, was not inorganic nanoparticles but cationic polystyrene spheres of $103 \mathrm{~nm}$ in diameter, assembled onto soft poly(ethyl acrylate-co-ethyleneglycol dimethacrylate-co-methacrylic acid) latex spheres of $714 \mathrm{~nm}$ [22].

$\mathrm{Xu}$ et al. heterocoagulated cationic PMMA latex particles of an estimated $150-200 \mathrm{~nm}$ in diameter with various clays, Montmorillonite (GelWhite GP and Cloisite $\mathrm{Na}^{+}$) and (fluoro)hectorites (Laponite RD, RDS, B, S, JS), having plate dimensions between 25 and $600 \mathrm{~nm}$. No details on the stable colloidal armored structures were reported. Mass coagulation was induced in order to obtain a nanocomposite bulk material, which was further analyzed [23]. Chen et al. [24] added $\mathrm{TiO}_{2}$ and $\mathrm{SiO}_{2} / \mathrm{TiO}_{2}$ nanoparticles with a positive surface charge at a very low $\mathrm{pH}$ of $0-2$ to both anionic and cationic latexes based on PMMA. A bulk nanocomposite blend was analyzed.

Voorn et al. heterocoagulated both anionic "hard" polystyrene and "soft" poly (iso-butyl methacrylate) latex particles onto large positively charged gibbsite clay platelets. The soft latex was allowed to spread and wet the surface of the clay platelets to form a more uniform layered film by curing at $80^{\circ} \mathrm{C}$ [25] (see Fig. 4). At low number ratios of latex particles to clay platelets (i.e., <180) multilayered aggregates were formed. Increasing the amount of latex particles resulted in coverage of isolated clay particles. The use of small latex particles at low ionic strength proved beneficial to warrant overall colloidal stability [26]. 

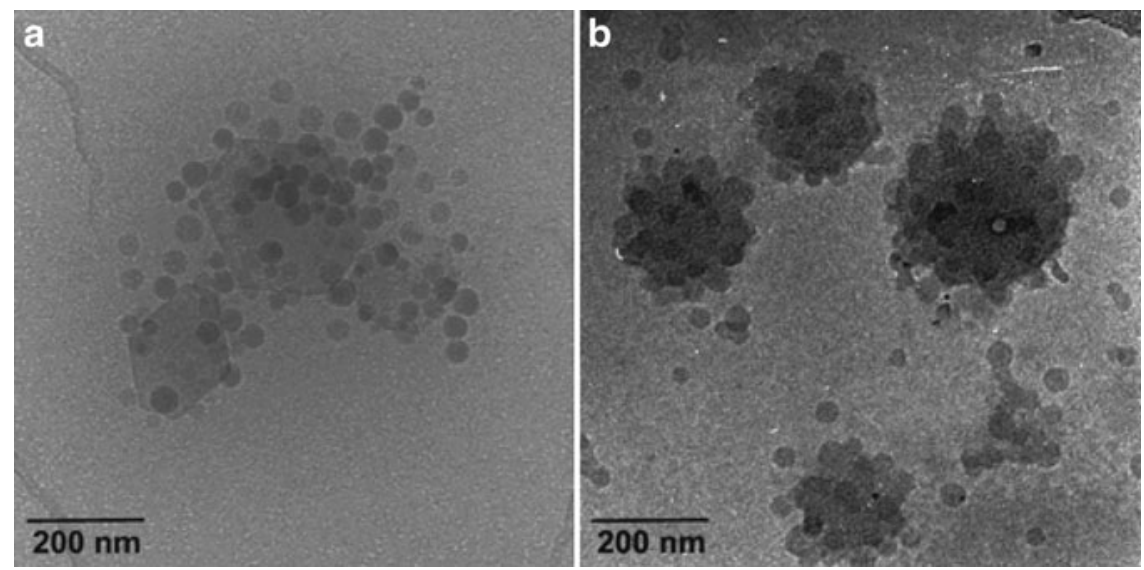

Fig. 4 Cryo-TEM micrographs of cationic gibbsite with anionic poly(iso-butyl methacrylate) latex particles at different $\mathrm{NaCl}$ concentrations: (a) $3.1 \times 10^{-4} \mathrm{M}$ and (b) $9.1 \times 10^{-4} \mathrm{M}$. The image is a reproduction of Fig. 8 from [25]

\subsection{Hydrophobic Interactions}

It is common knowledge that amphiphilic molecules, such as sodium dodecyl sulfate, above a certain critical concentration in water form assembled structures in which the hydrophobic units are clustered together. The notice of a "hydrophobic effect" was brought to light by Walter Kauzmann, whilst studying forces that influenced protein denaturation [27]. An excellent critical review on interfaces and the driving forces of hydrophobic assembly was written by Chandler in 2005 [28].

The hydrophobic effect is the tendency of nonpolar species to cluster in water in order to decrease the overall interfacial area between the hydrophobic species and water. It can be seen as predominantly driven by the large cohesive energy of water. Clustering of a set of individual hydrophobic particles into an agglomerate structure initially looks entropy driven. However, one should look at the overall change in free energy, and thus also at enthalpy. The latter is a measure of the average potential energy of interaction between molecules. Assembly processes that involve considerable changes in the number of molecular interactions, therefore could (also) be enthalpy driven.

There have been numerous attempts to define hydrophobic interactions, but there is no single one that can explain all experimental results [29]. In 1989, Eriksson [30] postulated that the long-range hydrophobic interactions (LRHFs) occurred due to structural changes on the boundary layers of water when in contact with hydrophobic surfaces. Attard [29] pointed out that the likely origin of the long-range hydrophobic forces is the formation of nanobubbles. Stillinger has suggested that the interface of liquid water near a large hydrophobic particle can be modeled analogously to a water-vapor interface [31]. 
Yaminsky et al. [32] evaluated theoretically a hydrophobic surface in water with a contact angle of more than $90^{\circ}$ and concluded that the water-vapor cavity is thermodynamically favored at small separations.

The existence of such a hydrophobic "gap" between liquid water and the hydrophobic surface has been experimentally confirmed by, for example, Mezger and coworkers using high-resolution X-ray studies at the water-octadecyltrichlorosilane interface [33]. The reason is that the persistence of a hydrogen-bonded network of water molecules is geometrically impossible on a "large" (in excess of $\sim 1 \mathrm{~nm}$ ) interface, and therefore leads to drying. This dewetting effect can lead to very strong interactions between hydrophobic objects, as seen for example in surface force measurements. When two hydrophobic objects approach each other, water is depleted from the region between the two objects [34].

These hydrophobic interactions are reported to be "long-range" commonly covering distances of 1-100 $\mathrm{nm}$ [35], greatly exceeding the interaction range of van der Waals forces. Singh and coworkers [36] investigated the hydrophobic effect between naturally occurring superhydrophobic rough surfaces (water contact angle of $170^{\circ}$ ) beneath a water surface, using force measurements in which a superhydrophobic tip was placed in contact with a flat superhydrophobic substrate, both immerged in water, the tip being subsequently retracted. They found a very-long-range hydrophobic interaction that was due to out-of-contact "cavitation" of the intervening water at tip-to-substrate separations ranging from $0.8 \mu \mathrm{m}$ to an impressive $3.5 \mu \mathrm{m}$. Cavitation is a first-order phase transition, which was the reason for the observed sudden, strong attractive force identified as a vapor bridge spanning the tip-to-substrate gap.

Nagai and coworkers reported a study of heterocoagulation driven by the hydrophobic effect of cationically charged "hard" poly[styrene-co-(methacryloyloxyphenyl-dimethylsulfonium methylsulfate)], or "soft" poly[styrene-co-(butyl acrylate)-co-(methacryloyloxyphenyl-dimethylsulfonium methylsulfate)] latex particles of ca. 220-240 nm in diameter onto neutral microspheres of crosslinked polystyrene $(8.5 \mu \mathrm{m}$ in diameter) [37]. A separate study on the small cationic latex particles showed that their interface was hydrophobic, as the cationic surfactant cetyltrimethylammonium bromide (CTAB) adsorbed onto the surface, clearly driven by a hydrophobic effect [38]. The assembly of the cationic latex particles onto the larger microspheres was studied against increasing $\mathrm{NaCl}$ concentrations, which influenced the packing patterns from individually spaced to clusters (see Fig. 5).

\subsubsection{Self-Assembly of Amphiphilic Particles Driven by the Hydrophobic Effect}

An interesting "molecular" approach using the hydrophobic effect to assemble gold nanoparticles was taken by Zubarev and coworkers who attached V-shaped (twin-tailed) amphiphilic polystyrene-block-poly(ethylene oxide) with a central carboxylic acid moiety (which binds to the gold nanoparticle), effectively giving biphasic, Janus-type characteristics [39]. Self-assembly led to wormlike aggregates (see Fig. 6). 

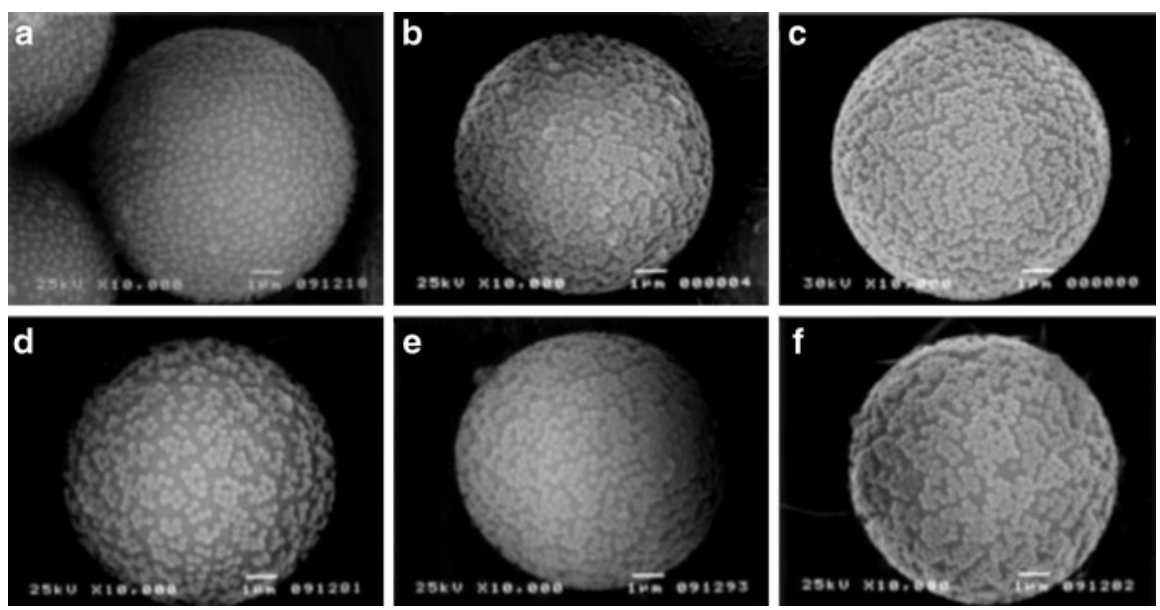

Fig. 5 SEM photographs of cationic polymer latex particles heterocoagulated onto the surface of crosslinked polystyrene microspheres driven by the hydrophobic effect, against increasing $\mathrm{NaCl}$ concentrations. "Hard" poly[styrene-co-(methacryloyloxyphenyl-dimethylsulfonium methylsulfate)] particles at (a) 0.5, (b) 50, and (c) $200 \mathrm{mM}$ of $\mathrm{NaCl}$. "Soft" poly[styrene-co-(butyl acrylate)-co-(methacryloyloxyphenyldimethylsulfonium methylsulfate)] latex particles at (d) 0.5 , (e) 50 , and (f) $200 \mathrm{mM}$ of $\mathrm{NaCl}$

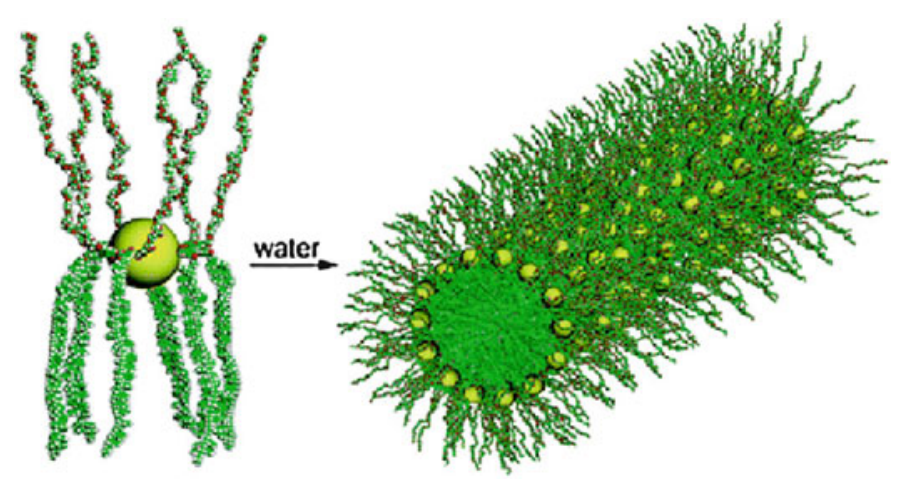

Fig. 6 Representation of the amphiphilicity-driven self-assembly of Au-(PS-PEO) nanoparticles (for simplicity reasons only six PS-PEO molecules are shown). This figure is a reproduction of Fig. 1A from [39]

Along this line of using amphiphilic features of particles to drive assembly using a hydrophobic effect, there has been a recent surge of interest in the fabrication and behavior of anisotropic "patchy" or Janus-type colloidal particles as a promising route to innovative nanocomposite materials [40,41]. Whereas a thorough review lies outside our scope, we would like to highlight a few examples. Müller and coworkers prepared disc-like polymer Janus particles from assem- 
bled films of polystyrene-block-poly(butadiene)-block-PMMA triblock copolymer (SBM) [42], selective crosslinking of the poly(butadiene) block, and dissolution via sonication, and then assembled them into supracolloidal Janus micelles. They revisited this in another paper and described the hydrolysis of the PMMA into poly(methacrylic acid) [43]. Again, assembly into supracolloidal micelles was driven by the hydrophobic effect. Chen and coworkers prepared polymeric Janus particles from divinylbenzene (DVB) and $N$-isopropylacrylamide (NIPAM) via an yttrium hydroxide nanotube (YNT)-supported route. On removal from their support, these asymmetric particles assembled into flower-like supracolloidal structures (see Fig. 7) [44].
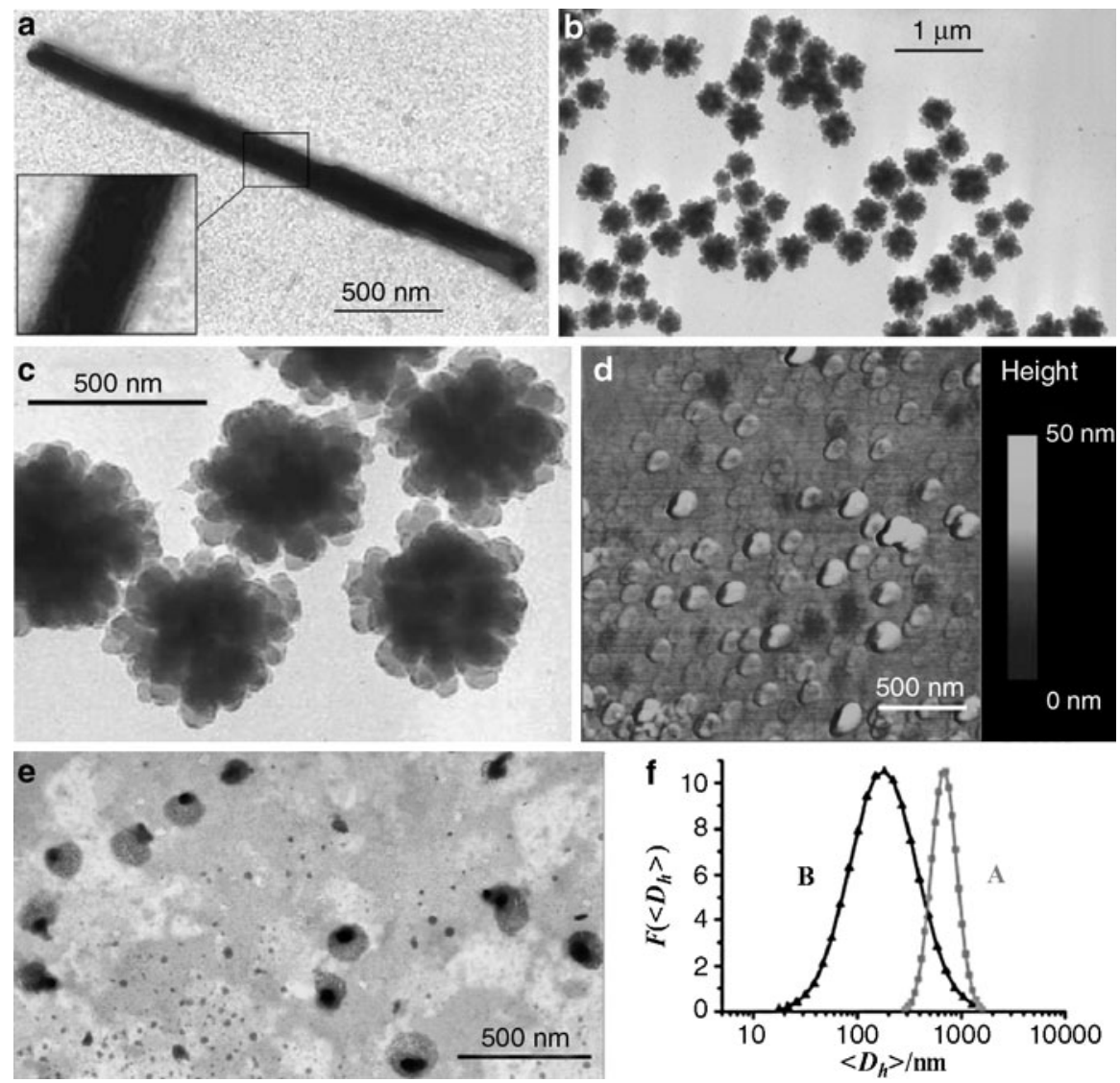

Fig. 7 (a) TEM image of a hybrid nanotube. Inset at higher magnification shows the polymer layer surrounding the yttrium hydroxide nanotube (YNT). (b) TEM image of the supermicelles. (c) TEM image of the supermicelles at a larger magnification. (d) AFM image of petal-like (Janus) particles that result from the dissociation of the supermicelles on mica. (e) TEM image of the Janus particles stained with $\mathrm{RuO}_{4}$. (f) Distribution of the hydrodynamic diameter $\left\langle D_{\mathrm{h}}>\right.$ of the supermicelles $(A)$ and the Janus particles $(B)$. This figure is reproduced from Fig. 2 in [44] 
Granick and coworkers studied, both experimentally and by Monte Carlo simulations, the assembly of amphiphilic colloidal microspheres into clusters [45]. Not only supracolloidal spherical micellar structures were observed, but also wormlike strings. Fluorescent carboxylated polystyrene microspheres were partially coated (hemisphere) with a thin gold layer, the latter subsequently being modified with octadecanethiol to promote a hydrophobic nature. The hemisphere with the free carboxylate groups was occasionally made more hydrophilic by grafting of DNA oligomers onto the surface of the microsphere. With increasing salt concentration $\left(\mathrm{KNO}_{3}\right)$, a transition from unimers, spherical clusters, and wormlike strings was observed in both simulations and experiments.

Recently, Miller and Cacciuto explored the self-assembly of spherical amphiphilic particles using molecular dynamics simulations [46]. They found that, as well as spherical micellar-type structures and wormlike strings, also bilayers and faceted polyhedra were possible as supracolloidal structures. Whitelam and Bon [47] used computer simulations to investigate the self-assembly of Janus-like peanut-shaped nanoparticles and found phases of clusters, bilayers, and nonspherical and spherical micelles, in accordance with a packing parameter that is used conventionally and in analogy to predict the assembled structures for molecular surfactants. They also found faceted polyhedra, a structure not predicted by the packing parameter (see Fig. 8). In both studies, faceted polyhedra and bilayers coexist, a phenomenon that is still unexplained.
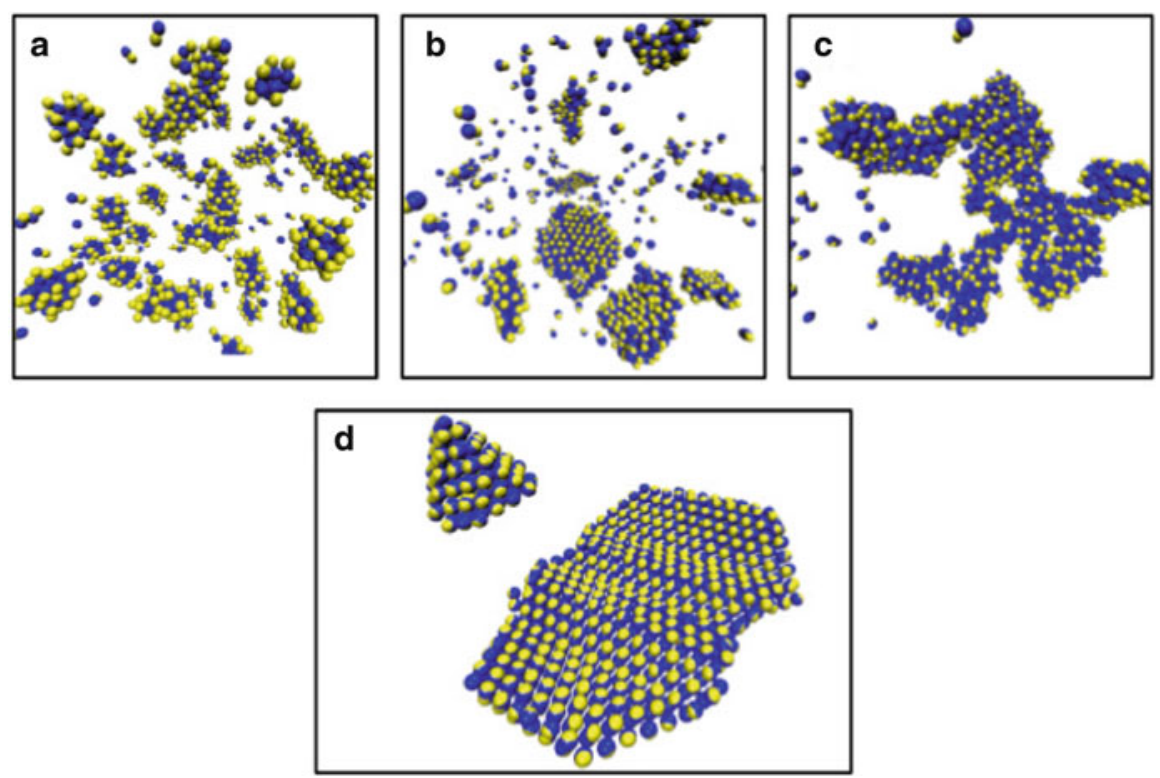

Fig. 8 Various configurations for assembled peanut-shaped amphiphilic nanoparticles of variable particle geometry. (a) Micelles of various morphologies; (b) coexisting bilayers and micelles, (c) disordered wormlike micelle, and (d) coexisting polygon and bilayer. This figure is reproduced from Fig. 6 in [47] 


\subsection{Secondary Molecular Interactions}

Beyond electrostatic and hydrophobic forces, the heterocoagulation process could be controlled by secondary molecular interactions. We will briefly highlight with some examples the hydrogen bonding, $\pi-\pi$ interactions, and specific molecular interactions obtained from complementary DNA strands, and biotin-avidin complexation.

\subsubsection{Hydrogen Bonding}

Hydrogen bonding is one of the most common interactions that can aid the assembly process of colloidal particles. Hydrogen bonding is an attractive interaction of a hydrogen atom with an electronegative atom (typically oxygen, nitrogen, or fluorine) and, strengthwise, typically lies between van der Waals and ionic attractions. We restrict ourselves to mentioning some typical examples.

Armes and coworkers studied the preparation of polypyrrole particles in the presence of silica sols [48, 49]. Hydrogen bonding between the silica surface and the polypyrrole particles, in addition to electrostatic and hydrophobic interactions, led to raspberry-shaped nanocomposite colloids.

Yang and coworkers [50] assembled particles of poly(ethylene glycol dimethacrylate-co-acrylic acid) [poly(EGDMA-co-AA)] onto larger poly(ethylene glycol dimethacrylate-co-4-vinylpyridine) [poly(EGDMA-co-VPy)] microspheres to form a core-corona structure with a raspberry-like polymer composite. They used a hydrogen interaction mechanism through an affinity complex between the carboxylic acid group and pyridine group.

Li et al. [51] prepared monodisperse microspheres by distillation precipitation polymerization of DVB and NIPAM with 2,2-azobisisobutyronitrile (AIBN) as initiator in acetonitrile, in the absence of any surfactant. Next, latex particles of poly(EGDMA-co-AA) were assembled onto the microspheres to afford a corecorona composite polymer particle with a raspberry-like morphology, strengthened by hydrogen-bonding interaction.

\subsection{2 $\pi-\pi$ Interactions}

$\mathrm{Li}$ and coworkers [52] described the formation of supracolloidal balls with a mean diameter of $148 \pm 5 \mathrm{~nm}$ by self-assembly of $\mathrm{Fe}_{3} \mathrm{O}_{4}$ nanoparticles $(6.0 \pm 1.3 \mathrm{~nm})$ that were functionalized with 2-carboxyterthiophene (TTP-COOH). The driving force behind self-assembly in DMF was shown to be $\pi-\pi$ stacking of the thiophene units (see Fig. 9). 

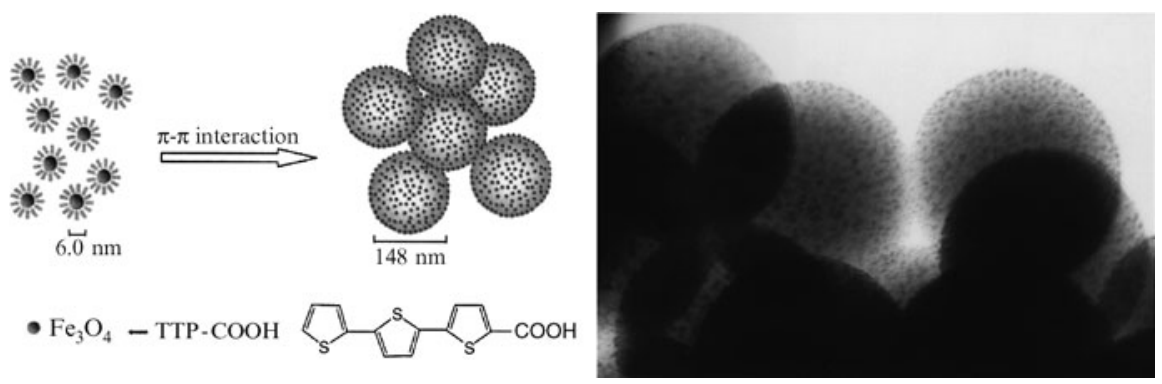

Fig. 9 Structure model proposed for the self-assembly process of individual nanoparticles to form microspheres through $\pi-\pi$ interactions $(l e f t)$. The sizes of individual nanoparticles and microspheres can be determined directly from TEM images (right). Figure reproduced from Figs. 2 and 3 from [52]

\subsubsection{Specific Recognition of Complementary DNA Strands}

An interesting approach using specific multiple hydrogen-bond recognition is the functionalization of nanoparticles with DNA-based oligonucleotides. Mirkin and coworkers [53] functionalized two batches of Au colloids of $13 \mathrm{~nm}$ diameter dispersed in water with separate non-complimentary oligonucleotides, i.e., 3 -thiol-TTTGCTGA and 3'-thiol-TACCGTTG. Combination of the two separate functionalized gold nanoparticles led to a stable colloidal sol, the grafted oligonucleotides providing steric stabilization and thereby improving the stability of the sol to increasing temperature and/or electrolyte concentration. Aggregation of the gold nanoparticles was achieved by addition of a duplex consisting of 5'-ATGGCAACTATACGCGCTAG and 3'-ATATGCGCGATCTCAGCAAA, containing eight-base-pair sticky ends, complementary to the gold sols.

Valignat [54] demonstrated that this powerful assembly method could be used to lock reversibly directed assembled (with optical tweezers) microspheres grafted with complementary polymer brushes into a prearranged suprastructure (see Fig. 10).

\subsubsection{Avidin-Biotin Recognition}

There are alternatives to complementary DNA strand recognition, for example the strong interaction between avidin (or its related streptavidin) and biotin. Avidin is a tetrametric glycoprotein that has the ability to interact strongly with up to four biotin units. Biotin, also known as vitamin $\mathrm{H}$ or B7, is a soluble B complex of ureido(tetrahydroimidizalone) ring fused with a tetrahydrothiophene ring. The interaction between avidin and biotin is widely explored. An interesting example related to heterocoagulation of small polystyrene particles on larger silica microspheres was 

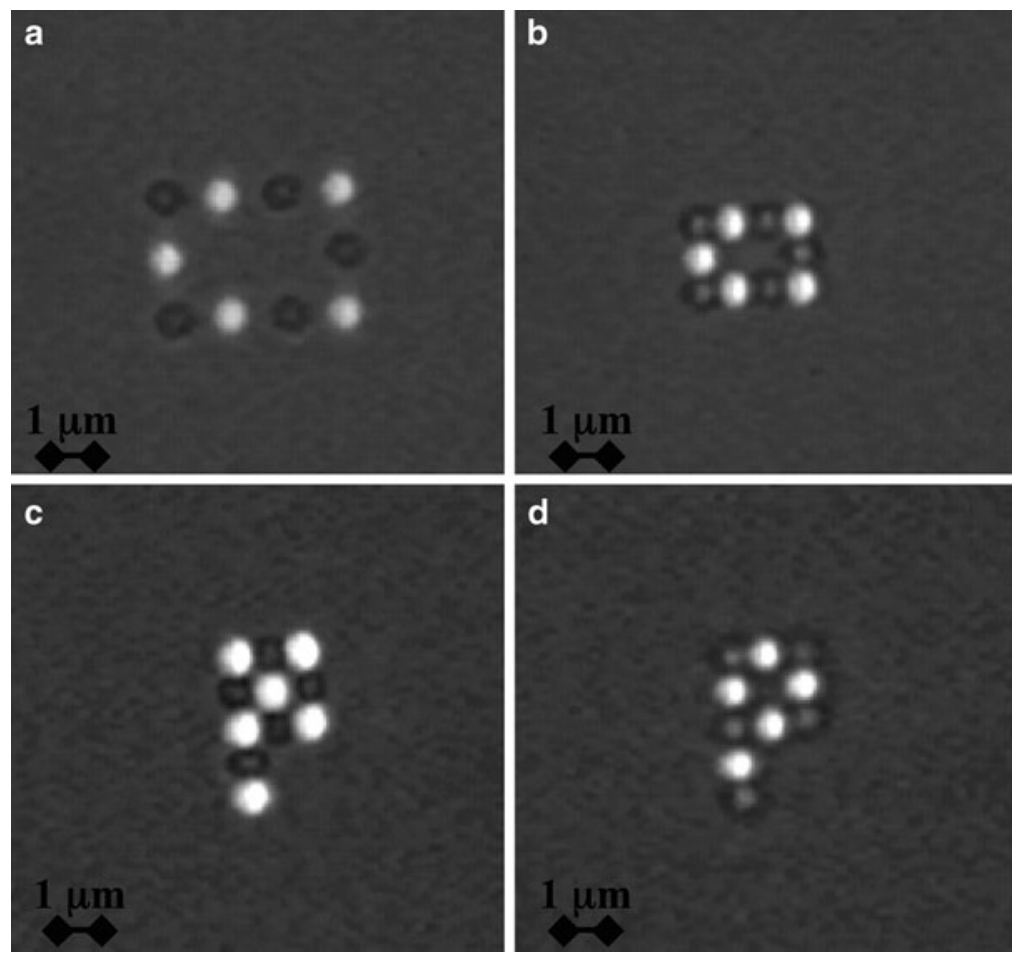

Fig. 10 Directed assembly of particles. Fluorescent and nonfluorescent particles bear complementary strands of DNA. (a) Particles are first captured in discrete time-shared traps induced by laser tweezers. (b-d) Particles are moved in contact to promote hybridization between the DNA strands and form the following rigid structures: a rectangle (b), a "full" P (c), and an "empty" P (d). This figure is reproduced from Fig. 4 in [54]

reported by Fleming and coworkers [55]. Amine-functionalized silica microspheres of $5 \mu \mathrm{m}$ diameter were either treated with biotin sulfosuccinimdyl ester, or reacted with avidin after activation of the silica spheres with gluteraldehyde. Biotin-labeled polystyrene particles of ca. $200 \mathrm{~nm}$ in diameter were made in a similar manner. However, avidin-labeled polystyrene particles were obtained by treatment of the biotin-labeled ones with excess amounts of avidin. Upon mixing the complementary colloids, strong adhesion of the polystyrene particles onto the surface of the silica spheres was observed. From earlier work by Chern [56], it should be noted that avidin is not able to induce flocculation of biotin-labeled particles (diameter $\sim 549 \mathrm{~nm}$ ), because its size $(\sim 4 \mathrm{~nm})$ is not large enough to bridge the overlapping double layers of the particles. The armored structure obtained by Fleming [57] is strengthened by the biotin-avidin interaction, although the heterocoagulation process itself is not induced by it. 


\section{Assembly of Nanoparticles onto Prefabricated Larger Particles via Repetitive Heterocoagulation: the Layer-by-Layer Technique}

The layer-by-layer (LbL) technique for the assembly of nanoparticles onto a substrate can be seen as a repetitive extension of heterocoagulation. Driving forces for adhesion can in theory be based on the same interactions, i.e., electrostatic, hydrophobic, and secondary molecular interactions. For example, in the case of LbL assembly driven by electrostatic interactions, alternating layers of positively and negatively charged particles and/or (macro)molecules are deposited sequentially onto the underlying substrate, the latter obviously also undergoing surface charge-inversion in inverse alternating fashion [58]. Hydrogen bonding as a driving force to LbL self-assembly was investigated by Rubner et al. [59] and Zhang et al. $[60,61]$. The LbL technique based on biotin-avidin recognition was described by Osa $[62,63]$.

The excess amount of material used is removed between steps. The LbL technique is easy to carry out and very versatile. Because of this, a great range of polyelectrolytes, biopolymers (proteins and nucleic acids), lipids, and inorganic particles have been used as building blocks in the preparation of multilayer composite films [64, 65], and in the fabrication of micro- and nanometer-sized capsules, the latter introduced in 1998 by Donath and Caruso [66-68].

Caruso et al. [69] reported the preparation of negatively charged polystyrene latex particles $(640 \mathrm{~nm}$ diameter) armored with a nanocomposite multilayer of $\mathrm{SiO}_{2}$ nanoparticles (Ludox TM-40; $26 \pm 4 \mathrm{~nm}$ diameter) and poly(diallyldimethylammonium chloride) (PDADMAC). These two components were sequentially adsorbed onto the surface of the polystyrene latex spheres (see Fig.11), after adsorption of a precursor polyelectrolyte multilayer film of PDADMAC/

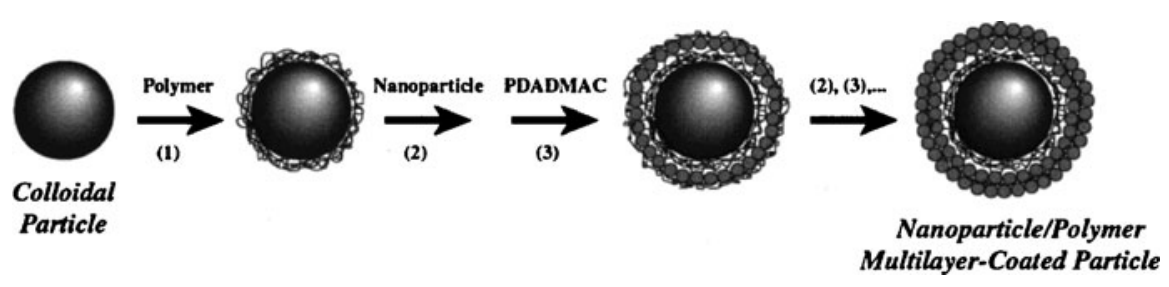

Fig. 11 Preparation of multilayer-coated particles. The first stage involves the formation of a three-layer polyelectrolyte multilayer film [PDADMAC/poly(sodium 4-styrenesulfonate)/ PDADMAC], formed by the sequential adsorption of PDADMAC and poly(sodium 4-styrenesulfonate) under conditions where they are oppositely charged (step 1). The outermost layer, PDADMAC, positively charged, aids the subsequent adsorption of negatively charged $\mathrm{SiO}_{2}$ nanoparticles. $\mathrm{SiO}_{2}$ /PDADMAC multilayer shells on the polystyrene latexes are then formed by the sequential adsorption of $\mathrm{SiO}_{2}$ (step 2) and PDADMAC (step 3). Additional $\mathrm{SiO}_{2}$ and PDADMAC cycles result in further growth of the multilayer shell thickness on the PS latexes. The excess/unadsorbed polyelectrolyte and nanoparticles are removed by a series of centrifugation/water wash/redispersion cycles before additional layers are deposited. Figure and legend taken from [69] 
poly(sodium 4-styrenesulfonate)/PDADMAC, which provided a uniformly charged surface and facilitated subsequent $\mathrm{SiO}_{2}$ nanoparticle adsorption. The process was driven by electrostatic interactions. Using electrophoretic mobility (EPM) measurements, reversal of the $\zeta$-potential after each deposition step was shown. Single-particle light scattering (SPLS) measurements showed the linear increase of the particle dimensions upon increasing $\mathrm{SiO}_{2}$ /PDADMAC multilayer number. Electron microscopy showed the evidence of a stepwise multilayer growth, with TEM data yielding an average diameter increment of ca. $65 \mathrm{~nm}$, corresponding to a layer thickness of approximately $32 \pm 5 \mathrm{~nm}$ for each $\mathrm{SiO}_{2} / \mathrm{PDADMAC}$ layer pair. A similar approach was undertaken using nanoparticles of $\mathrm{Fe}_{3} \mathrm{O}_{4}$ (diameter $10-15 \mathrm{~nm})$ [69].

\section{Assembly of Nanoparticles onto Emulsion Monomer Droplets and their Subsequent Polymerization}

In the previous section, we have seen that "hard" inorganic nanoparticles can adhere onto the surface of polymer latex particles via a stochastic process of collisions, which was referred to as heterocoagulation. Once deposited onto the surface of the latex particles, the strength of adhesion governed by attractive forces such as electrostatic attraction, the hydrophobic effect, and hydrogen bond interactions needs to outbalance repulsive forces and the entropy gain achieved when nanoparticles detach. This potential detachment of nanoparticles from the surface of the polymer latex particle is typically induced by the thermal energy of the system, $k_{\mathrm{B}} T$ (where $k_{\mathrm{B}}$ is the Boltzmann constant and $T$ is temperature).

What happens if we replace the polymer latex particle with a monomer droplet onto which we had first assembled the "hard" nanoparticles and then polymerized the now-armored droplet?

\subsection{Pickering Stabilization: Adhesion of Particles to "Soft" Interfaces}

The phenomenon whereby solid particles adhere onto an emulsion droplet (i.e., a liquid-liquid interface) was first observed and reported by Ramsden [70] and Pickering [71] in the 1900s. They found that these emulsion droplets were stable against coalescence, because the adhered solid particles effectively provided a barrier. Emulsions stabilized by adhered solid particles were coined Pickering emulsions [72, 73]. Hildebrand et al. [74] suggested that the reason the particles place themselves in the liquid-liquid interface is that they partially wet the two liquid phases. In line with the Bancroft rule for emulsification, which links whether a water-in-oil or oil-in-water emulsion is preferred for a certain type of emulsifying agent, the authors suggested that the type of emulsion produced by a solid powder 
is determined by the contact angle between the solid and the liquid-liquid interface: "In order for the powder to remain in the interface the angle must be finite, and unless the angle is $90^{\circ}$, the interface will be on one side or the other of the points of contact of the particles, and its tension will cause the film to be concave on that side" [74].

The observations by Ramsden and Pickering that emulsion droplets armored with solid particles were "stable" against coalescence suggests that the particles are in essence trapped and cannot leave the interface to re-enter one of the two liquid phases.

\subsubsection{Interaction of a Single Spherical Particle with a "Soft" Interface}

Pieranski [75] developed a simple macroscopic model to calculate the free energy as a function of the position of a spherical particle with respect to the "soft" liquid-liquid (or, as was the case in his manuscript, a liquid-air interface). In this macroscopic continuous model, three interfacial energy $(E)$ contributions can be derived as the product of the interfacial tension and the respective contact areas (see Fig. 12 for illustration of $r$ and $z$ ):

$$
\begin{aligned}
& E_{\mathrm{p} 1}=\gamma_{\mathrm{p} 1} 2 \pi r^{2}\left(1+\frac{z}{r}\right) \\
& E_{\mathrm{p} 2}=\gamma_{\mathrm{p} 2} 2 \pi r^{2}\left(1-\frac{z}{r}\right) \\
& E_{12}=-\gamma_{12} \pi r^{2}\left(1-\left(\frac{z}{r}\right)^{2}\right)
\end{aligned}
$$

$\gamma_{\mathrm{p} 1}, \gamma_{\mathrm{p} 2}$, and $\gamma_{12}$ are the interfacial tensions between the particle and liquid phase 1 , the particle and liquid phase 2 , and the two liquid interfaces. When we define the following dimensionless numbers:

$$
z_{0}=\frac{z}{r} ; \sigma_{1}=\frac{\gamma_{\mathrm{p} 1}}{\gamma_{12}} ; \sigma_{2}=\frac{\gamma_{\mathrm{p} 2}}{\gamma_{12}} ; E_{0}=\frac{E_{\mathrm{p} 1}+E_{\mathrm{p} 2}+E_{12}}{k_{\mathrm{B}} T}
$$

Fig. 12 Interaction of a sphere with a liquid-liquid interface on a macroscopic scale and in a continuous fashion. $r$ radius of the sphere; $z$ distance from the centre of the sphere to the interface

liquid phase 1

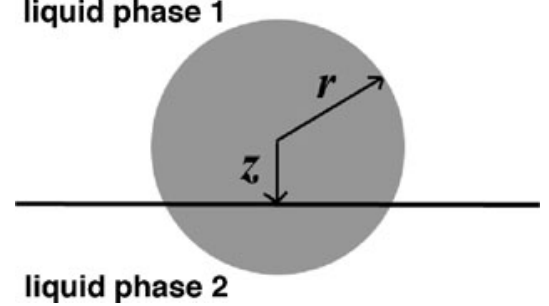


we find for the relative free energy $E_{0}$ :

$$
E_{0}=\left[\frac{\gamma_{12} \pi r^{2}}{k_{\mathrm{B}} T}\right]\left(z_{0}^{2}+2\left(\sigma_{1}-\sigma_{2}\right) z_{0}+2 \sigma_{1}+2 \sigma_{2}-1\right)
$$

The equilibrium position for the particle can easily be found from:

$$
\begin{aligned}
& \frac{\mathrm{d} E_{0}}{\mathrm{~d} z_{0}}=2 z_{0}+2\left(\sigma_{1}-\sigma_{2}\right)=0 \\
& z_{0}^{\min }=\sigma_{2}-\sigma_{1}
\end{aligned}
$$

For values of $z_{0}^{\min }$ between -1 and 1 , the particle adheres to the liquid-liquid interface. The energy it will take to remove the particle from the interface into either the bulk of phase 1 or phase 2 can easily be obtained from:

$$
\begin{aligned}
& \Delta E_{1}=E_{0}\left(z_{0}=1\right)-E_{0}\left(z_{0}^{\min }\right) \\
& \Delta E_{2}=E_{0}\left(z_{0}=-1\right)-E_{0}\left(z_{0}^{\min }\right)
\end{aligned}
$$

Whereas this model gives a good feel for the order of magnitude of the energy well in which the particles are trapped, it is rather crude and thus a simplification of reality. It does ignore surface charges (chemical heterogeneity of the surface, or "patchiness") and potential morphological surface roughness of the spherical particle, and as previously mentioned it assumes absence of external fields (such as gravity), or flow. A problem also ignored is the three-phase interaction at the contact line between the two liquids and the particle. Gibbs already suggested qualitatively that this three-phase contact line should be treated as a one-dimensional "line tension", in analogy with the two-dimensional surface tension between the interphase of two bulk phases. An expression for the free energy as a function of particleinterface separation for a spherical particle of radius $R$, extended to account for line tension $(\tau)$, was given by Aveyard and Clint [76], in which they basically added one extra term to the Pieranski equation:

$$
E_{0}=\left[\frac{\gamma_{12} \pi r^{2}}{k_{\mathrm{B}} T}\right]\left(z_{0}^{2}+2\left(\sigma_{1}-\sigma_{2}\right) z_{0}+2 \sigma_{1}+2 \sigma_{2}-1\right)+\frac{2 \pi r \tau}{k_{\mathrm{B}} T} \sqrt{\left(1-z_{0}^{2}\right)}
$$

As can be seen from this expression, the effect of line tension becomes increasingly important for smaller spherical particles as it scales linearly with the radius of the particle, whereas contributions arising from interfacial tensions scale quadratically. A debate on experimentally realistic values of line tension is ongoing, especially when the spherical particles become of nanoscale dimensions and line tension may become important. 
One key question that remains is what is the validity of these macroscopic models when we scale the size of our spherical particle down to nanoscale dimensions? The liquid-liquid interface can no longer be modeled as flat (capillary waves need to be considered), and additional small-scale effects, such as discrete rather than continuous wetting of the spherical nanoparticle by the liquid molecules, need to be taken into account. Can this be reflected in line tension?

Cheung and Bon [77] used molecular simulations to investigate the behavior of a non-charged nanoparticle in proximity and adhered to an ideal liquid-liquid interface. In the model, a two-component Widom-Rowlinson (WR) fluid [78] was used to generate the two phase-separated bulk liquids and the corresponding soft interface, thereby neglecting electrostatic and attractive van der Waals forces. Calculated free energy profiles as function of the distance of the nanoparticle from the soft liquidliquid interface confirmed that macroscopic models, such as the Pieranski model [75], gave a poor description of the energy well. The energy well was considerably wider, and thus the distance of interaction greater, between the particle and the interface. The reason for this is most probably due to the existence of capillary waves (the liquid-liquid interface can no longer be considered flat). Moreover, the smaller the nanoparticle, the larger the underestimation of the depth of the energy well by the Pieranski model, with deviations of up to $50 \%$. The binding energy was found to increase quadratically with the radius of the nanoparticle, with an additional linear dependency (which could plausibly be seen as line tension). The overall good news from these simulations is that nanoparticles adhere considerably stronger to, and are trapped over a longer range by, the liquid-liquid interface than predicted by macroscopic models.

A question often asked is whether the parabolic energy wells as predicted by Pieranski have an activation barrier that prevents the particle from "falling" in spontaneously. One can argue that, especially for a large spherical particle, upon its approach to the soft interface, the interface needs to deform and liquid has to drain. This event adds an activation barrier that needs to be overcome for the particle not to bounce off the interface, and clearly the interfacial tension between the two soft bulk phases (liquid-liquid and liquid-air) and the viscosity of both phases play key roles. Note that a potential hydrophobic effect [28] can counterbalance such a barrier because the dewetting of the liquid between a hydrophobic particle and the hydrophobic liquid phase, or air, stimulates long-range attraction and eases the adhesion process.

Obviously one also should take into account the shape of the particle, as often the particles used will differ from spheres. This can clearly have dramatic effects on where and how the particle adheres to the interface when it tries to minimize energy from interfacial as well as line tensions. The three-point contact angle needs to be constant, which means that the contact line must undergo curvature in order to accommodate this. This has a pronounced influence on the interaction (of a longrange nature) between adhered particles on the surface. An in-depth discussion lies outside the scope of this review, but the interested reader is referred to (as a starting point) work by Vermant and coworkers [79, 80]. 


\subsubsection{Droplets Armored with a Layer of Adhered Particles}

The above discussion only considers the existence of a single isolated particle on a liquid-liquid interface. Experimentally, however, the number of nanoparticles adhered to a single monomer droplet or growing polymer particle will be greater than unity. This means that particle-particle interactions, both attractive and/or repulsive in nature, need to be taken into account. An elegant example confirming the existence of attractive particle-particle interactions can be found in work reported by Russell and coworkers [81]. They prepared a dispersion of $2.8 \mathrm{~nm}$ (diameter) tri- $n$-octylphosphine (TOPO)-covered cadmium selenide (CdSe) nanoparticles in toluene. Upon introduction of a water droplet, the nanoparticles organized themselves onto the toluene-water interface. Introduction of $4.6 \mathrm{~nm}$ (diameter) CdSe nanoparticles let to displacement of the smaller ones from the liquid-liquid interface. A clear phase-separation was seen on the surface of the water droplet, showing distinct regions of the 2.8 and $4.6 \mathrm{~nm}$ CdSe nanoparticles, respectively.

When particles of a narrow particle size distribution (monodisperse) adhere to the interface of a spherical droplet, 2D crystallization can occur. As a direct result of the curved surface of the droplet, packing into infinite hexagonal 2D arrays is no longer possible. The determination of the packing geometry is often referred to as the Thomson problem [82], generalized by Tammes. In short, there are 12 packing defects, either in the form of point dislocations or grain boundary scars (the latter for large droplets, which have a greater number of particles on the surface). Bausch et al. $[83,84]$ showed that for large droplets onto which thousands of microspheres were assembled, this rule of 12 defects prevailed in the form of five- and seven-neighbor line defects, or grain boundary scars. Bon and coworkers [85] studied a system of intermediate size (tens to hundreds of particles on a sphere), i.e., the packing patterns of silica nanoparticles on polystyrene latex particles made via Pickering miniemulsion polymerization [86, 87]. They found an excellent correlation between the experimental morphology and the nearest-neighbor distribution using metropolis Monte Carlo simulations, using a 12-24Lennard-Jones potential. Moreover, they addressed the effect of the polydispersity of the nanoparticles used in preparing the armored droplets. They found that upon broadening of the particle size distribution, the packing geometry could no longer be described in terms of 12-point dislocations or grain boundary scars [85].

\subsection{Polymerization of Emulsion Droplets Armored with Inorganic Nanoparticles: Pickering Suspension and Miniemulsion Polymerization}

We have seen from the above discussion that solid particles can adhere to a "soft" interface, and thus to monomer droplets. The effect of Pickering stabilization protects the droplets from coalescence. The use of solid particles as stabilizers in emulsion-based polymerization techniques was first described in open literature by 
Hohenstein [88, 89] for suspension polymerizations in the 1940s. Winslow and Martreyek [90] investigated the influence of both solid inorganic particles such as bentonite and $\mathrm{Ca}_{3}(\mathrm{PO})_{4}$ and organic stabilizers on the suspension polymerization of mixtures of DVB with ethylvinylbenzene. Wiley [91], in 1954, showed that monomer droplets of styrene dispersed in water in the presence of Dowex-50 ionexchange resin beads or bentonite clay led to adhesion of the solid particles onto the surface of the droplets. The Pickering-stabilized droplets underwent so-called limited coalescence, a process that after a certain time period effectively yielded a stable set of solids-armored liquid droplets. Pickering stabilization could be promoted upon addition of, for example, gelatin and/or inorganic salts. Assuming monolayer adsorption of the colloid onto the surface of the monomer liquid droplets, Wiley was able to predict the average droplet size by assuming cubic (square) packing of spherical solid particles onto a spherical monomer droplet. This yielded the following equation, after a slight addition from Bon et al. to account for coverage:

$$
R_{\mathrm{mon}}=C \pi\left(\frac{m_{\mathrm{mon}}}{m_{\mathrm{part}}}\right)\left(\frac{\rho_{\mathrm{part}}}{\rho_{\mathrm{mon}}}\right) R_{\mathrm{part}}
$$

in which $R_{\text {mon }}$ is the radius of the monomer droplet, $R_{\text {part }}$ the radius of the spherical Pickering stabilizer, $C$ accounts for coverage (for full monolayer coverage following 2 D square or cubic packing $C=1$ ), and $m$ and $\rho$ stand for the masses and densities, respectively.

In suspension polymerization, inorganic solids such as hydroxyapatite $\left[3 \mathrm{Ca}_{3}\right.$ $\left.\left(\mathrm{PO}_{4}\right)_{2} \cdot \mathrm{Ca}(\mathrm{OH})_{2}\right]$ are often used in conjunction with (polymeric) surfactants. Deslandes [92] reported in 1987 a study in which he investigated the morphology of the beads obtained in the suspension copolymerization of styrene and butadiene. A thin layer composed of very uniformly distributed hydroxyapatite particles was adhered to the surface of the polymer bead, and surrounded by a thicker and flakier layer of loosely packed agglomerates of hydroxyapatite and small polymer beads, which were also covered by a monolayer of inorganic matter. Despite this paper, studies on the use of solid particles in suspension polymerization remained focused on their effective use as stabilizers.

A shift of interest in the area of Pickering suspension polymerization towards the morphologies of the polymerized emulsion droplets was reported by Bon and coworkers [93-96]. They demonstrated that microgels of poly(methyl methacrylateco-divinylbenzene) could be used to stabilize emulsion droplets composed of various monomers, i.e., styrene, DVB, and $n$-butylacrylate [93]. A substantial amount of hexadecane was added as porogen. Upon Pickering suspension polymerization, the in situ generated polymer phase separated towards the interface and formed an interpenetrating network with the microgel particles. A variety of microcapsules with a raspberry-type morphology were synthesized. They showed the fabrication of $\mathrm{TiO}_{2}$ nanoparticle (ca. $150 \mathrm{~nm}$ in diameter) armored microspheres and capsules made via Pickering suspension polymerization of styrene and DVB. For the capsules hexadecane was used as non-solvent for the polymer [95]. Upon polymerization, the polymer phase-separated at the interface of the 
droplet. The average size of the capsules could be varied by altering the amount of $\mathrm{TiO}_{2}$ nanoparticles. The polymer wall thickness could be controlled by variation of the monomer to hexadecane ratio. They also reported on the fabrication of complex silica-based microcapsules via a two-stage templating route [97] in which nanocomposite polystyrene latex particles armored with Laponite clay discs (made via Pickering miniemulsion polymerization) were used as Pickering stabilizer of emulsion droplets containing poly(diethoxysilane) and oil. Upon hydrolysis and sol-gel reaction of the poly(diethoxysilane), hollow capsules were obtained. The organic components could be removed via an additional calcination step. The capsule walls could be decorated on either the outside or inside with nanocapsules composed of Laponite clay.

A variety of other nanoparticles have been used in Pickering suspension polymerizations, including magnetic $\mathrm{Fe}_{3} \mathrm{O}_{4}$ [98-100] and $\mathrm{CdS}$ nanoparticles stabilized by poly(ethylene glycol-block-styrene-block-2-(dimethylamino) ethyl methacrylate) [101].

$\mathrm{Wu}$ and coworkers [102] reported on the inverse Pickering suspension polymerization of $\mathrm{N}$-isopropyl acrylamide (NIPAM). They used various sizes of silica particles, ranging from 53 to $962 \mathrm{~nm}$ in diameter, as solids stabilizer. Suspension polymerizations were successful for the silica particles of diameter $<500 \mathrm{~nm}$. Similar work was reported by Wang and coworkers. [103].

Bon and Kumacheva and coworkers [104] demonstrated that monodisperse solids-stabilized droplets could be generated in a microfluidic flow focusing device, whereby the solid particles were initially present in the dispersed phase. Polymerization of the monomer droplets led to hybrid polymer microspheres. They also showed that non-spherical particles could be obtained by geometric confinement of the droplets in the channel [104, 105].

A logical extension from Pickering suspension polymerization would be to miniaturize the size of the droplets into the regime of miniemulsion polymerization. Landfester and coworkers [106] described miniemulsion copolymerizations of styrene with 4-vinylpyridine in presence of Ludox TMA silica nanoparticles. The use of 4-vinylpyridine was required to warrant the fabrication of armored latex particles. Bon and coworkers [87] described the Pickering miniemulsion polymerization of styrene using Laponite RD clay discs as solids stabilizer in the absence of any auxiliary comonomer or surfactant. In a detailed mechanistic study [86], they reported that this Pickering miniemulsion polymerization using Laponite clay discs (ca. $25 \mathrm{~nm}$ in diameter and $1 \mathrm{~nm}$ in height) was successful and yielded armored polymer latexes for a variety of hydrophobic monomers, including styrene, lauryl(meth)acrylate, butyl(meth)acrylate, octylacrylate, and 2 ethylhexylacrylate. Studying the polymerization rates, they found a pronounced retardation effect up to intermediate conversion, which was more prominent for smaller particles. A model was presented that allowed for prediction of the average particle sizes of the latexes produced as function of the amounts of monomer and clay discs used. A linear relationship between the number of clay discs used and the total surface area of the latex particles was shown. Key herein was that the sonication process to prepare the armored miniemulsion droplets warranted reversible adhesion of the Laponite 
clay discs throughout the emulsification step. Bon and coworkers [85] also performed Pickering miniemulsion polymerizations of styrene using spherical silica nanoparticles of approximately $25 \mathrm{~nm}$ in diameter (Ludox TM-40), in which the packing arrangements of the silica nanoparticles on the surface were investigated and modeled with the aid of Monte Carlo simulations. Zhang and coworkers used organically modified silica nanoparticles to carry out a Pickering miniemulsion polymerization of styrene [107]. The co-use of sodium dodecyl sulfate (SDS) and 2-(methacryloyl) ethyltrimethylammonium chloride (MTC) as auxiliary monomer was also reported in the Pickering miniemulsion polymerization of styrene stabilized by silica nanoparticles [108].

Bon, Keddy, and coworkers [109] demonstrated that "soft" armored polymer latex made via Pickering miniemulsion polymerization [i.e., poly(lauryl acrylate) armored with Laponite clay discs] could be used as a nanocomposite additive in standard poly(butyl acrylate-co-acrylic acid) waterborne pressure-sensitive adhesives (PSAs), leading to marked mechanical property enhancements (see Fig. 13).

Fig. 13 (a) Comparison of the probe-tack stress-strain curves for the model PBA adhesive in the presence of $2.7 \mathrm{wt} \%$ clay-armored soft-hard hybrid particles with the equivalent amount of non-armored PLA (2.45 wt \%), Laponite clay discs $(0.25 \mathrm{wt} \%)$, and a blend of non-armored PLA $(2.45 \mathrm{wt} \%)$ and Laponite clay $(0.25 \mathrm{wt} \%)$. (b) Synergistic effect of PLA-nanoclay hybrid particles on the tack energy of the model PSA. The increase in the tack energy above PBA is given as a function of the nanofiller content. Figure and legend are taken from [109]

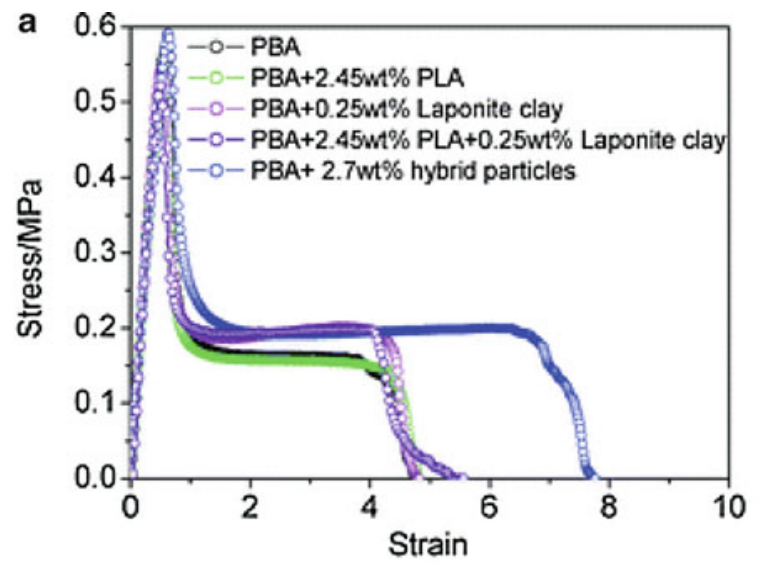

Clay content wt\%

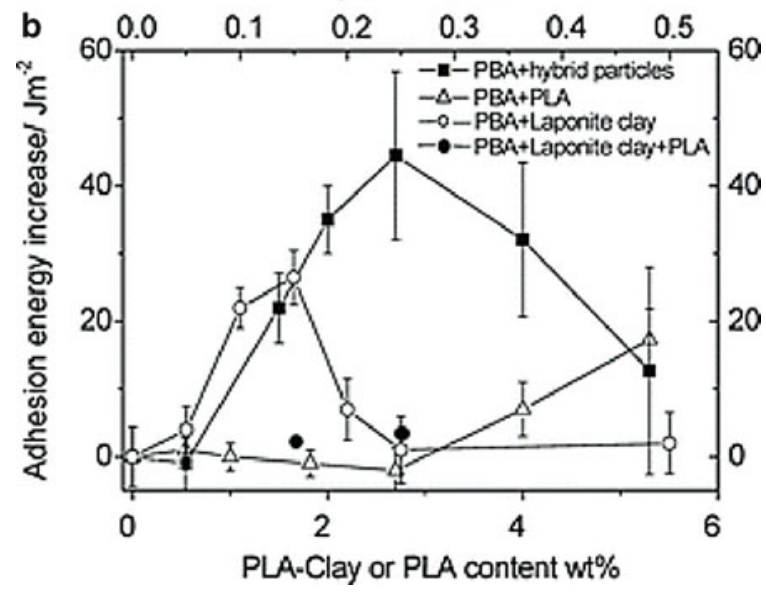


A maximum tack energy enhancement of $45 \mathrm{Jm}^{-2}$ was found in nanocomposite PSAs containing $2.7 \mathrm{wt} \%$ hybrid particles, which was about $70 \%$ greater than found for the PBA adhesive alone. In comparison, the tack energy for nanocomposites containing an equivalent amount of non-armored PLA, Laponite clay discs, or both did not lead to increases of the same magnitude, therefore showing a synergistic effect as a direct result of the supracolloidal armored structure of the clay poly(lauryl acrylate) additive.

Voorn and coworkers demonstrated the inverse Pickering miniemulsion polymerization of aqueous acrylamide and 2-hydroxyethyl methacrylate in cyclohexane using hydrophobically modified Montmorillonite platelets (cloisite 20A) as solids stabilizer [110].

\section{Assembly of Nanoparticles onto the Surface of Polymer Colloids Throughout Emulsion Polymerization: Solids-Stabilized, or Pickering, Emulsion Polymerization}

The use of a high-energy homogenization step to prepare the submicrometer-sized monomer droplets for the Pickering miniemulsion process could be a drawback for industrial scale-up. A better outcome could be achieved by the equivalent emulsion polymerization process in which solid nanoparticles were used as solids stabilizer.

Müller and coworkers prepared disc-like polymer Janus particles from assembled films of the triblock copolymer SBM and, after hydrolysis of the ester groups into methacrylic acid units, used these as Pickering stabilizer in the soap-free emulsion polymerization of styrene and butyl acrylate [111]. Armes and coworkers described the synthesis of PMMA/silica nanocomposite particles in aqueous alcoholic media using silica nanoparticles as stabilizer [112], extending this method to operate in water with a glycerol-modified silica sol [113, 114]. Sacanna showed that methacryloxypropyltrimethoxysilane [115] in the presence of nanosized silica led to spontaneous emulsification in water, which upon a two-step polymerization procedure afforded armored particles with an outer shell of PMMA [116]. Bon and coworkers demonstrated the preparation of armored hybrid polymer latex particles via emulsion polymerization of methyl methacrylate and ethyl methacrylate stabilized by unmodified silica nanoparticles (Ludox TM-40) [117]. Performance of an additional conventional seeded emulsion polymerization step provided a straightforward route to more complex multilayered nanocomposite polymer colloids (see Fig. 14).

The use of either styrene or butyl methacrylate as monomer led to stable latexes that were not covered by silica particles. Bon and coworkers proposed a mechanism for the solids-stabilized, or Pickering, emulsion polymerization that effectively combines coagulative nucleation with heterocoagulation throughout the polymerization process. The growing latex particles become unstable and collide irreversibly with the nanoparticles that are dispersed in the water phase. The key to successful polymerization is that this collision process is fast with respect to the timescales of particle nucleation and growth. 


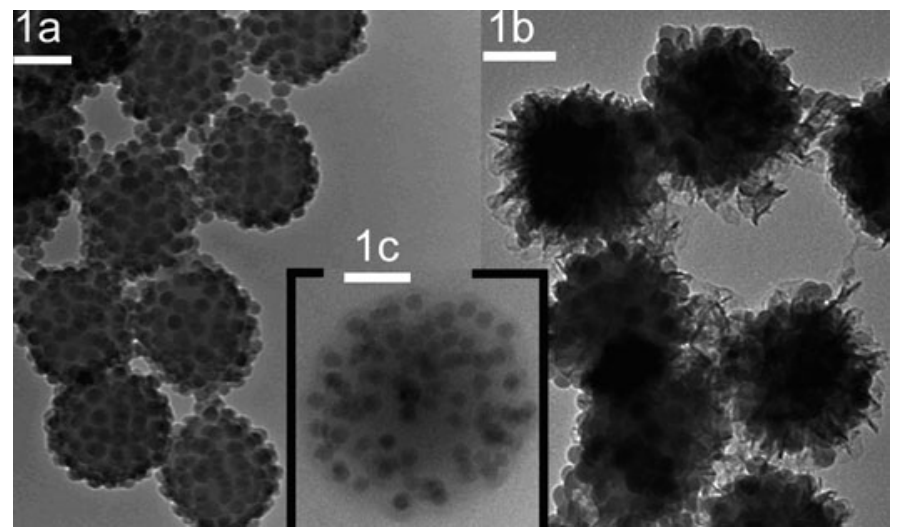

Fig. 14 TEM images of (a) PMMA latex armored with silica nanoparticles obtained by Pickering emulsion polymerization. Multilayered nanocomposite polymer colloids with (b) a "hairy" outerlayer of poly(acrylonitrile) and (c) a soft shell of poly(n-butyl acrylate). Scale bars: $100 \mathrm{~nm}$. Figure and legend are taken from [117]

$\mathrm{Wu}$ and coworkers studied the silica-nanoparticle-stabilized emulsion polymerization of vinyl acetate, with the aid of a small amount of anionic reactive surfactant, 3-allyloxy-2-hydroxy-1-propanesulfonic acid sodium salt (HAPS) [118]. They argued that hydrogen bond interactions allowed for strong adhesion, and also commented on the mechanism of solids-stabilized emulsion polymerization.

Bon and coworkers carried out a study on the fate of the nanoparticles throughout solids-stabilized emulsion polymerization [119]. A quantitative method based on disk centrifugation was developed to monitor the amount of nanoparticles present in the water phase in solids-stabilized emulsion polymerizations of vinyl acetate, methyl methacrylate, and butyl acrylate. The concentration profile of nanoparticles in the water phase as a function of monomer conversion agreed with theoretical models developed for the packing densities in these systems [120]. Noteworthy was that in the case of silica-nanoparticle-stabilized emulsion polymerization of vinyl acetate, the event of late-stage limited coalescence, leading to small armored nonspherical clusters, could be predicted and explained on the basis of the concentration profiles and particle size measurements. Adjusting the amount of silica nanoparticles prevented this phenomenon.

Ma and Dai [121] reported the synthesis of polystyrene latexes armored with silica nanoparticles $(10-15 \mathrm{~nm}$ in diameter, PA-ST silica sol, Nissan Chemicals) via solids-stabilized emulsion polymerization. They used VA-086, 2,2'-azobis [2-methyl- $N$-(2-hydroxyethyl)propionamide], as nonionic initiator. Whereas we found that Pickering emulsion polymerization of styrene using Ludox TM-40 and a low flux of radicals generated from potassium persulfate did not result in an armored latex, the hydroxyethyl groups probably enhance the wettability of the surface of the latex particles to promote silica adhesion. This was confirmed by a 
study undertaken by Bourgeat-Lami [122], who showed that poly(ethylene glycol) monomethylether methacrylate (PEGMA) macromonomer aided the adhesion of silica nanoparticles in the surfactant-free solids-stabilized emulsion polymerization of styrene. They also noticed a reduced overall rate of polymerization due to the presence of the nanoparticles on the surface of the growing latex particles, which was earlier observed by Bon and Colver [123] in Pickering miniemulsion polymerizations. Similar results of reduced polymerization rates were reported by Zhang and coworkers, who studied the silica-nanoparticle-stabilized emulsion polymerization of methyl methacrylate in presence of hydroxyethyl methacrylate [124]. Song and coworkers performed photocatalytic emulsion copolymerizations of styrene and EGDMA with auxiliary monomers of acrylic acid or sodium styrene sulfonate, and in the presence of a cationic titania hydrosol. They found that the auxiliary monomers greatly promoted adhesion of the titania nanoparticles onto the polymer latexes [125, 126].

\section{Hybrid Polymer Colloids Through Assembly of Colloidal Building Blocks via Interface-Driven Templating}

Mixtures of polymer latexes and inorganic colloids can be assembled into supracolloidal clusters with controlled spatial organization of the particles via geometric or interfacial-energy-driven confinement.

Pine and coworkers [127] confined particles to the interface of emulsion droplets, after which the fluid was evaporated, leading to specific packing arrangements that depended on the original number of spheres per liquid droplet (see Fig. 15). Clusters of colloidal spheres included doublets, triangles, tetrahedral and more exotic polyhedra. This was extended using various combinations of two different colloids with several size ratios in water-in-oil emulsions: monodisperse silica or polystyrene microspheres for larger particles, and silica or titania nanoparticles for smaller particles. Not only the size but also the adhesion behavior of the individual colloids at the water-oil interface played an important role. Packing predictions were carried out with Surface Evolver and corresponded to the experimentally observed structures [128]. A third paper addressed formation of composite colloids in toluene-in-water emulsions in which polystyrene was added as macromolecular glue [129].

Lee and Weitz showed that confinement of particles in the middle phase of double emulsion droplets and subsequent evaporation of this phase led to nanoparticle supracolloidal capsules [130], also referred to as colloidosomes [131].

Velegol used a so-called particle lithography technique in which colloids were deposited on a flat solid surface, after which heterocoagulation of macromolecules and or particles could take place on the exposed areas [132-135]. Anisotropic assemblies of colloids can be manufactured via this route.

Xia and coworkers demonstrated the assembly of colloids into well-defined clusters by dewetting of aqueous dispersions of monodisperse particles across surfaces patterned with two-dimensional arrays of templates or relief structures [136]. 
a
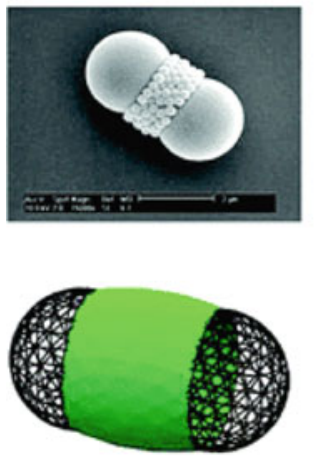

contact angle $=20^{\circ}$ volume $=r^{3}$
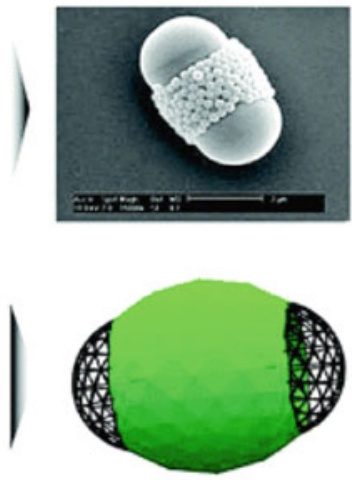

contact angle $=20^{\circ}$ volume $=5 \mathrm{r}^{3}$
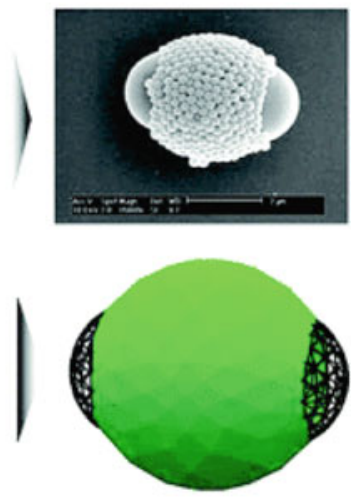

contact angle $=20^{\circ}$ volume $=10 \mathrm{r}^{3}$

b
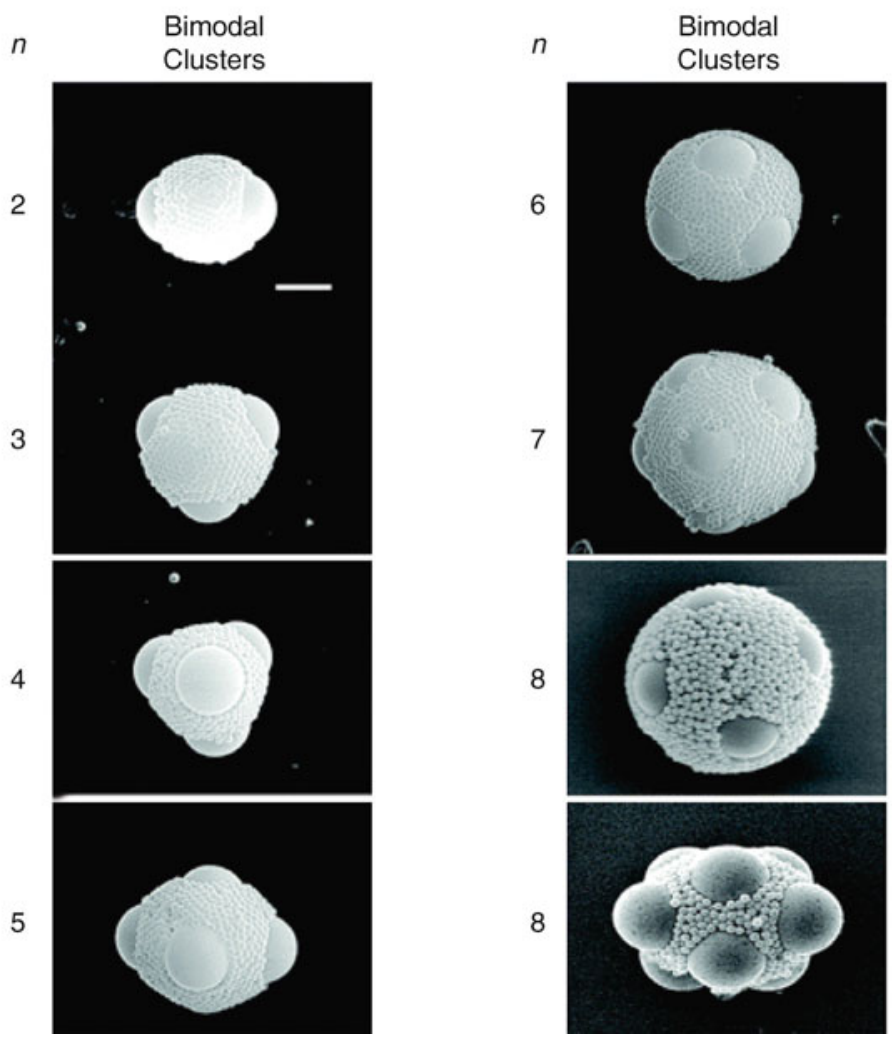

Bimodal

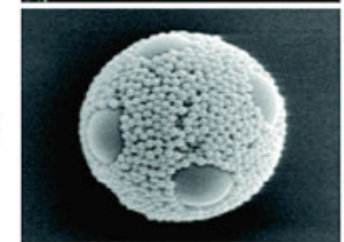

8

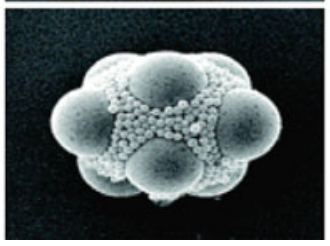

Fig. 15 (a) Top: SEM images for the structural evolution of bimodal colloidal clusters of silica microspheres and nanospheres for $n=2$. Bottom: Surface Evolver simulated structural evolution for $n=2$ as a function of the amount of silica nanospheres. (b) SEM images of silica-silica composite clusters for $n=2-8$. Scale bar: $2 \mu \mathrm{m}$. The size ratio of large and small silica particles was fixed at 10. Figure and legend are taken from Fig. 3 from [128] 


\section{Outlook}

We have seen in this review that there are a vast array of physical methods that we can make use of in the design of nanocomposite polymer colloids. The classical approach of heterocoagulation can undergo a renaissance by exploring driving forces such as the hydrophobic effect and secondary molecular interactions. Self-assembly of complex anisotropic colloidal particles is already creating a whole new direction in the fabrication of supracolloidal structures.

The behavior of nanoparticles at soft interfaces and their ability to adhere to these strongly has great potential for further studies, especially in the area of solids-stabilized emulsion polymerization. The ability to control and understand mechanistically this process will allow the design of innovative hybrid polymer colloids.

Creative methods of templating, whether in droplets or on hard patterned surfaces, together with advances in lithography and colloid visualization methods, will also contribute greatly to a wealth of innovative supracolloidal structures.

\section{References}

1. Derjaguin BV (1954) A theory of the heterocoagulation, interaction and adhesion of dissimilar particles in solutions of electrolytes. Discuss Faraday Soc 18:85-98

2. Jachowicz J, Berthiaume MD (1989) Heterocoagulation of silicon emulsions on keratin fibers. J Colloid Interface Sci 133(1):118-134

3. Derjaguin BV, Landau L (1941) Theory of stability of strongly charged lyophobic sols of the adhesion of strongly charged particles in solution electrolytes. Acta Physicochim USSR 14:633-662

4. Verwey EJW, Overbeek JTG (1948) Theory of the stability of lyophobic colloids. Elsevier, Amsterdam

5. Hamaker HC (1937) The London-van der Waals attraction between spherical particles. Phys Rev Lett 4:1058

6. Visser J (1972) Hamaker constants. comparison between Hamaker constants and Lifshitz-van der Waals constants. Adv Colloid Interface Sci 3: 331

7. Hogg R, Healy TW, Fuerstenau DW (1966) Mutual coagulation of colloidal dispersions. Trans Faraday Soc 62:1638

8. Barouch E, Matijevi E, Wright TH (1985) Double-layer interactions of unlike spheres. Part 2. Numerical analysis of electrostatic interaction energy. J Chem Soc Faraday Trans 81(1): $1819-1832$

9. Bleier A, Matijevic E (1976) Heterocoagulotion. I. Interactions of monodispersed chromium hydroxide with polyvinyl chloride latex. J Colloid Interface Sci 55(3):510-524

10. Luckham PF, Vincent B, McMahon J, Tadros TF (1983) The controlled flocculation of particulate dispersions using small particles of opposite charge. II. Investigation of floc structure using a freeze-fracture technique. Colloids Surf 6(1):83-95

11. Luckham PF, Vincent B, Tadros TF (1983) The controlled flocculation of particulate dispersions using small particles of opposite charge. III. Investigation of floc structure using rheological techniques. Colloids Surf 6(2):101-118

12. Luckham PF, Vincent B, Tadros TF (1983) The controlled flocculation of particulate dispersions using small particles of opposite charge. IV. Effect of surface coverage of adsorbed polymer on heteroflocculation. Colloids Surf 6(2):119-133 
13. Vincent B, Young CA, Tadros TF (1978) Equilibrium aspects of heteroflocculation in mixed sterically stabilised dispersions. Faraday Discuss Chem Soc 65296

14. Vincent B, Jafelicci M, Luckham PF, et al. (1980) Adsorption of small, positive particles onto large, negative particles in the presence of polymer. Part 2. Adsorption equilibrium and kinetics as a function of temperature. J Chem Soc Faraday Trans 1: Physical Chemistry in Condensed Phases 76:674-682

15. Hansen FN, Matijević E (1980) Heterocoagulation Part 5. Adsorption of a carboxylated polymer latex on monodispersed hydrated metal oxides. J Chem Soc Faraday Trans 1: Physical Chemistry in Condensed Phases 76:1240-1262

16. Barouch E, Matijevic E, Ring TA, Finlan JM (1978) Heterocoagulation II. Interaction energy of two unequal spheres. J Colloid Interface Sci 67(1):1-9

17. Furusawa K, Anzai C (1992) Heterocoagulation behaviour of polymer latices with spherical silica. Colloids Surf 63(1-2):103-111

18. Furusawa K, Anzai C (1987) Preparation of composite fine particles by heterocoagulation. Colloid Polym Sci 265:882-888

19. Harley S (1990) Ph.D. dissertation thesis, University of Bristol

20. Harley S, Thompson DW, Vincent B (1992) The adsorption of small particles onto larger particles of opposite charge - direct electron-microscope studies. Colloids Surf 62(1-2): $163-176$

21. Ottewill RH, Schofield AB, Waters JA, Williams NSJ (1997) Preparation of core-shell polymer colloid particles by encapsulation. Colloid Polym Sci 275:274-283

22. Okubo M, Lu Y, Wang Z (1999) Analysis of stepwise heterocoagulation for the preparation of soft core/hard shell composite polymer particles. Colloid Polym Sci 277:77-82

23. Xu Y, Brittain WJ, Xue C, Eby RK (2004) Effect of clay type on morphology and thermal stability of PMMA-clay nanocomposites prepared by heterocoagulation method. Polymer 45(11):3735-3746

24. Chen J-H, Dai C-A, Chen H-J, Chien P-C, Chiu W-Y (2007) Synthesis of nano-sized TiO2/poly(AA-co-MMA) composites by heterocoagulation and blending with PET. J Colloid Interface Sci 308(1):81-92

25. Voorn DJ, Ming W, van Herk AM, Bomans PHH, Frederik PM, Gasemjit P, Johanssmann D (2005) Controlled heterocoagulation of platelets and spheres. Langmuir 21(15):6950-6956

26. Voorn DJ, Ming W, Laven J, Meuldijk J, de With G, van Herk AM (2007) Plate-sphere hybrid dispersions: heterocoagulation kinetics and DLVO evaluation. Colloids Surf A Physicochemical Eng Asp 294(1-3):236-246

27. Kauzmann W (1959) Some forces in the interpretation of protein denaturation. Adv Protein Chem 14:1-63

28. Chandler D (2005) Interfaces and the driving force of hydrophobic assembly. Nature 437:640-647

29. Attard P (2003) Nanobubbles and the hydrophobic attraction. Adv Colloid Interface Sci 104(1-3):75-91

30. Eriksson JC, Ljunggren S, Claesson PM (1989) A phenomenological theory of long-range hydrophobic attraction forces based on a square-gradient variational approach. J Chem Soc Faraday Trans 2: Molecular and Chemical Physics (85):163-176

31. Stillinger FH (1982) Capillary waves and the inherent density profile for the liquid-vapor interface. J Chem Phys 76:1087-1091

32. Yaminsky VV, Yushchenko VS, Amelina EA, Shchukin ED (1983) Cavity formation due to a contact between particles in a nonwetting liquid. J Colloid Interface Sci 96(2):301-306

33. Mezger M, Reichert H, Schoeder S, Okasinski J, Schroeder H, Dosch H, Palms D, Ralston J, Honkimaeki V (2006) High-resolution in situ X-ray study of they hydrophobic gap at the water-octadecyl-trichlorosilane interace. PNAS 103(49):18401-18404

34. Lum K, Chandler D, Weeks JD (1999) Hydrophobicity at small and large length scales. J Phys Chem B 103:4570-4577

35. Pashley RM, McGuiggan PM, Ninham BW, Evans DF (1985) Attractive forces between uncharged hydrophobic surfaces: direct measurements in aqueous solution. Science 229(4718):1088-1089 
36. Singh S, Houston J, van Swol F, Brinker CJ (2006) Superhydrophobicity: drying transition of confined water. Nature 442:526

37. Yamaguchi K, Ito M, Taniguchi T, Kawaguchi S, Nagai K (2004) Preparation of core-shell composite polymer particles by a novel heterocoagulation based on hydrophobic interaction. Colloid Polym Sci 282(4):366-372

38. Yamaguchi K, Taniguchi T, Kawaguchi S, Nagai K (2001) Fabrication of polymer particle monolayer onto alkylated glass plates. Chem Lett 7:658

39. Zubarev ER, Xu J, Sayyad A, Gibson DJ (2006) Amphiphilic-driven organization of nanoparticles into discrete assemblies. J Am Chem Soc 128(47):15098-15099

40. Walther A, Mueller AHE (2008) Janus particles. Soft Matter 4(4):663-668

41. Wurm F, Kilbinger AFM (2009) Polymeric Janus asymmetric partices. Angew Chem, Int Ed 48(45):8412-8421

42. Erhardt R, Boeker A, Zettl H, Kaya H, Pyckhout-Hintzen W, Krausch G, Abetz V, Mueller AHE (2001) Janus micelles. Macromolecules 43(4):1069-1075

43. Erhardt R, Zhang M, Boeker A, Zettl H, Abetz C, Frederik P, Krausch G, Abetz V, Mueller AHE (2003) Amphiphilic Janus micelles with polystyrene and poly(methacrylic acid) hemispheres. J Am Chem Soc 125(11):3260-3267

44. Nie L, Liu S, Shen W, Chen D, Jiang M (2007) One-pot synthesis of amphiphilic polymeric Janus particles and their self-assembly into supermicelles with a narrow size distribution. Angew Chem Int Ed 46:6321-6324

45. Hong L, Cacciuto A, Luijten E, Granick S (2008) Clusters of amphiphilic colloidal spheres. Langmuir 24:621-625

46. Miller W, Cacciuto A (2009) Phys Rev E 80:21404

47. Whitelam S, Bon SAF (2010) Self-Assembly of amphiphilic peanut-shaped nanoparticles. J Chem Phys 132:074901

48. Maeda S, Armes SP (1993) Preparation of novel polypyrrole-silica colloidal nanocomposites. J Colloid Interface Sci 159(1):257-259

49. Maeda S, Armes SP (1994) Preparation and characterization of novel polypyrrole-silica colloidal nanocomposites. J Mater Chem 4(6):935-942

50. Li R, Yang X, Li G, Li S, Huang W (2006) Core-corona polymer composite particles by self-assembled heterocoagulation based on a hydrogen-bonding interaction. Langmuir 22(19):8127-8133

51. Li GL, Song YY, Yang XL, Huang WQ (2007) Preparation of poly(divinylbenzene-co$\mathrm{N}$-isopropylacrylamide) microspheres and their hydrogen-bonding assembly behavior for raspberry-like core-corona polymer composite. J Appl Polym Sci 104(2):1350-1357

52. Jin J, Iyoda T, Cao C, Song Y, Jiang L, Li TJ, Zhui DB (2001) Self-assembly of uniform spherical aggregates of magnetic nanoparticles through pi-pi interactions. Angew Chem Int Ed 40(11):2135-2138

53. Mirkin CA, Letsinger RL, Mucic RC, Storhoff JJ (1996) A DNA-based method for rationally assembling nanoparticles into macroscopic materials. Nature 382(6592):607-609

54. Valignat M-P, Theodoly O, Crocker JC, Russel WB, Chaikin PM (2005) Reversible selfassembly and directed assembly of DNA-linked micrometer-sized colloids. Proc Natl Acad Sci USA 102(12):4225-4229

55. Fleming MS, Mandal TK, Walt DR (2001) Nanosphere-microsphere assembly: methods for core-shell materials preparation. Chem Mater 13(6):2210-2216

56. Chern CS, Lee CK, Chen CY (1996) Biotin-modified submicron latex particles for affinity precipitation of avidin. Colloids Surf B Biointerfaces 7(1-2):55-64

57. Fleming MS, Mandal TK, Walt DR (2001) Nanosphere-microsphere assembly: methods for core-shell materials preparation. Chem Mater 13(6):2210-2216

58. Decher G (1997) Fuzzy nanoassemblies: toward layered polymeric multicomposites. Science 277(5330): 1232

59. Stockton WB, Rubner MF (1997) Molecular-level processing of conjugated polymers. 4. Layer-by-Layer manipulation of polyaniline via hydrogen-bonding interactions. Macromolecules 30(9):2717-2725 
60. Wang L, Wang Z, Zhang X, Shen J, Chi L, Fuchs H (1997) A new approach for the fabrication of an alternating multilayer film of poly(4-vinylpyridine) and poly(acrylic acid) based on hydrogen bonding. Macromol Rapid Commun 18(6):509-514

61. Zhang H, Wang D, Wang Z, Zhang X (2007) Hydrogen bonded layer-by-layer assembly of poly(2-vinylpyridine) and poly(acrylic acid): influence of molecular weight on the formation of microporous film by post-base treatment. Eur Polym J 43(7):2784-2791

62. Hoshi T, Anzai J-I, Osa T (1995) Controlled deposition of glucose oxidase on platinum electrode based on an avidin/biotin system for the regulation of output current of glucose sensors. Anal Chem 67(4):770-774

63. Anzai J-I, Kobayashi Y, Nakamura N, Nishimura M, Hoshi T (1998) Layer-by-layer construction of multilayer thin films composed of avidin and biotin-labeled poly(amine)s. Langmuir 15(1):221-226

64. Decher G, Lehr B, Lowack K, Lvov Y, Schmitt J (1994) New nanocomposite films for biosensors: layer-by-layer adsorbed films of polyelectrolytes, proteins or DNA. Biosens Bioelectron 9(9-10):677-684

65. Sukhorukov GB, Möhwald H, Decher G, Lvov YM (1996) Assembly of polyelectrolyte multilayer films by consecutively alternating adsorption of polynucleotides and polycations. Thin Solid Films 284-285:220-223

66. Caruso F, Caruso RA, Mohwald H (1998) Nanoengineering of inorganic and hybrid hollow spheres by colloidal templating. Science 282(5391):1111

67. Donath E (1998) Novel hollow polymer shells by colloid-templated assembly of polyelectrolytes. Angew Chem Int Ed 37:2202

68. Johnston APR, Cortez C, Angelatos AS, Caruso F (2006) Layer-by-layer engineered capsules and their applications. Curr Opin Colloid Interface Sci 11(4):203-209

69. Caruso F, Mohwald H (1999) Preparation and characterization of ordered nanoparticle and polymer composite multilayers on colloids. Langmuir 15(23):8276-8281

70. Ramsden W (1903) Separation of solids in the surface-layers of solutions and 'suspensions' (observations on surface-membranes, bubbles, emulsions, and mechanical coagulation). Preliminary account. Proc R Soc Lond Sect A 72:156-164

71. Pickering SU (1907) CXCVI. - Emulsions. J Chem Soc Trans 91:2001-2021

72. Aveyard R, Binks BP, Clint JH (2003) Emulsions stabilised solely by colloidal particles. Adv. Colloid Interface Sci 100-102:503-546

73. Binks BP (2002) Particles as surfactants - similarities and differences. Curr Opin Colloid Interface Sci 7(1,2):21-41

74. Finkle P, Draper HD, Hildebrand JH (1928) The theory of emulsification. J Am Chem Soc 45:2780-2788

75. Pieranski P (1980) Two-dimensional interfacial colloidal crystals. Phys Rev Lett 45(7): $569-572$

76. Aveyard R, Clint JH (1996) Particle wettability and line tension. J Chem Soc Faraday Trans 92:85-89

77. Cheung DL, Bon SAF (2009) Interaction of nanoparticles with ideal liquid-liquid interfaces. Phys Rev Lett 102(6):066103

78. Widom B, Rowlinson JS (1970) New model for the study of liquid-vapor phase transitions. J Chem Phys 52:1670-1684

79. Madivala B, Fransaer J, Vermant J (2009) Self-assembly and rheology of ellipsoidal particles at interfaces. Langmuir 25(5):2718-2728

80. Madivala B, Vandebril S, Fransaer J, Vermant J (2009) Exploiting particle shape in solid stabilized emulsions. Soft Matter 5(8):1717-1727

81. Lin Y, Skaff H, Emrick T, Dinsmore AD, Russell TP (2003) Nanoparticle assembly and transport at liquid-liquid interfaces. Science 299, (5604), 226-229

82. Thomson JJ (1904) On the structure of the atom: an investigation of the stability and periods of oscillation of a number of corpuscles arranged at equal intervals around the circumference of a circle; with application of the results to the theory of atomic structure. Philos Mag 7(39):237-265 
83. Bausch AR, Bowick MJ, Cacciuto A, Dinsmore AD, Hsu MF, Nelson DR, Nikolaides MG, Travesset A, Weitz DA (2003) Grain boundary scars and spherical crystallography. Science 299(5613):1716-1718

84. Lipowsky P, Bowick MJ, Meinke JH, Nelson DR, Bausch AR (2005) Direct visualization of dislocation dynamics in grain-boundary scars. Nat Mater 4(5):407-411

85. Fortuna S, Colard CAL, Troisi A, Bon SAF (2009) Packing patterns of silica nanoparticles on surfaces of armored polystyrene latex particles. Langmuir 25(21):12399-12403

86. Bon SAF, Colver PJ (2007) Pickering miniemulsion polymerization using Laponite clay as a stabilizer. Langmuir 23(16):8316-8322

87. Cauvin S, Colver PJ, Bon SAF (2005) Pickering stabilized miniemulsion polymerization: preparation of clay armored latexes. Macromolecules 38(19):7887-7889

88. Hohenstein WP (1945) The method of polymerization in suspension Polym Bull 1(1):13-16

89. Hohenstein WP, Mark H (1946) Polymerization of olefins and diolefins in suspension and emulsion. I. J Polym Sci 1:127-45

90. Winslow FH, Matreyek W (1951) Particle size in suspension polymerization. J Ind Eng Chem 43:1108-1112

91. Wiley RM (1954) Limited coalescence of oil droplets in coarse oil-in-water emulsions. J Colloid Sci 9:427-437

92. Deslandes Y (1987) Morphology of hydroxyapatite as suspension stabilizer in the polymerization of poly(styrene-co-butadiene). J Appl Polym Sci 34(6):2249-2257

93. Bon SAF, Cauvin S, Colver PJ (2007) Colloidosomes as micron-sized polymerisation vessels to create supracolloidal interpenetrating polymer network reinforced capsules. Soft Matter 3(2):194-199

94. Bon Stefan AF, Chen T (2007) Pickering stabilization as a tool in the fabrication of complex nanopatterned silica microcapsules. Langmuir 23(19):9527-9530

95. Chen T, Colver PJ, Bon SAF (2007) Organic-inorganic hybrid hollow spheres prepared from TiO2-stabilized Pickering emulsion polymerization. Adv Mater 19(17):2286-2289

96. Colver PJ, Chen T, Bon SAF (2006) Supracolloidal structures through liquid-liquid interface driven assembly and polymerization. Macromol Symp 245:34-41

97. Bon SAF, Chen T (2007) Pickering stabilization as a tool in the fabrication of complex nanopatterned silica microcapsules. Langmuir 23(19):9527-9530

98. Wang C, Zhang C, Li Y, Chen Y, Tong Z (2009) Facile fabrication of nanocomposite microspheres with polymer cores and magnetic shells by Pickering suspension polymerization. React Funct Polym 69(10):750-754

99. Hasell T, Yang J, Wang W, Li J, Brown PD, Poliakoff M, Lester E, Howdle SM (2007) Preparation of polymer-nanoparticle composite beads by a nanoparticle-stabilised suspension polymerisation. J Mater Chem 17:4382-4386

100. Yang J, Hasell T, Wang W, Li J, Brown PD, Poliakoff M, Lester E, Howdle SM (2008) Preparation of hybrid polymer nanocomposite microparticles by a nanoparticle stabilized dispersion polymerization. J Mater Chem 18:998-1001

101. Chen K, Yang Y, Sa Q, Shi L, Zhao H (2008) Suspension polymerization stabilized by triblock copolymer with CdS nanoparticles. Polymer 49(11):2650-2655

102. Duan L, Chen M, Zhou S, Wu L (2009) Synthesis and characterization of poly(N-isopropylacrylamide)/silica composite microspheres via inverse Pickering suspension polymerization. Langmuir 25(6):3467-3472

103. Gao Q, Wang C, Liu H, Wang C, Liu X, Tong Z (2009) Suspension polymerization based on inverse Pickering emulsion droplets for thermo-sensitive hybrid microcapsules with tunable supracolloidal structures. Polymer 50(12):2587-2594

104. Nie Z, Park JI, Li W, Bon SAF, Kumacheva E (2008) An "inside-out" microfluidic approach to monodisperse emulsions stabilized by solid particles. J Am Chem Soc 130(49):16508-16509

105. Bon SAF, Mookhoek SD, Colver PJ, Fischer HR, van der Zwaag S (2007) Route to stable non-spherical emulsion droplets. Eur Polym J 43(11):4839-4842

106. Tiarks F, Landfester K, Antonietti M (2001) Silica nanoparticles as surfactants and fillers for latexes made by miniemulsion polymerization. Langmuir 17(19):5775-5780 
107. Zhang K, Wu W, Meng H, Guo K, Chen JF (2009) Pickering emulsion polymerization: Preparation of polystyrene/nano-SiO2 composite microspheres with core-shell structure. Powder Technol 190(3):393-400

108. Zhang Y, Chen H, Shu X, Zou Q, Chen M (2009) Fabrication and characterization of raspberry-like $\mathrm{PSt} / \mathrm{SiO} 2$ composite microspheres via miniemulsion polymerization. Colloids Surf A Physicochem Eng Asp 350(1-3):26-32

109. Wang T, Colver PJ, Bon SAF, Keddie JL (2009) Soft polymer and nano-clay supracolloidal particles in adhesives: synergistic effects on mechanical properties. Soft Matter 5(20): 3842-3849

110. Voorn DJ, Ming W, Van Herk AM (2006) Polymer-clay nanocomposite latex particles by inverse Pickering emulsion polymerization stabilized with hydrophobic montmorillonite platelets. Macromolecules 39(6):2137-2143

111. Walther A, Hoffmann M, Mueller AHE (2008) Emulsion polymerization using Janus particles as stabilizers. Angew Chem Int Ed 47(4):711-714

112. Percy MJ, Amalvy JI, Randall DP, Armes SP, Greaves SJ, Watts JF (2004) Synthesis of vinyl polymer-silica colloidal nanocomposites prepared using commercial alcoholic silica sols. Langmuir 20(6):2184-2190

113. Schmid A, Tonnar J, Armes SP (2008) A new highly efficient route to polymer-silica colloidal nanocomposite particles. Adv Mater 20(17):3331-3336

114. Schmid A, Armes SP, Leite CAP, Galembeck F (2009) Efficient preparation of polystyrene/silica colloidal nanocomposite particles by emulsion polymerization using a glycerol-functionalized silica sol. Langmuir 25(4):2486-2494

115. Sacanna S, Philipse AP (2007) A generic single-step synthesis of monodisperse core/shell colloids based on spontaneous Pickering emulsification. Adv Mater 19(22):3824-3826

116. Sacanna S, Kegel WK, Philipse AP (2007) Thermodynamically stable Pickering emulsions. Phys Rev Lett 98(15):158301

117. Colver PJ, Colard CAL, Bon SAF (2008) Multilayered nanocomposite polymer colloids using emulsion polymerization stabilized by solid particles. J Am Chem Soc 130(50):16850-16851

118. Wen N, Tang Q, Chen M, Wu L (2008) Synthesis of $\mathrm{PVAc} / \mathrm{SiO}_{2}$ latices stabilized by silica nanopartices. J Colloid Interface Sci 320(1):152-158

119. Colard Catheline AL, Teixeira RFA, Bon Stefan AF (2010) Unraveling mechanistic events in solids-stabilized emulsion polymerization by monitoring the concentration of nanoparticles in the water phase. Langmuir ASAP, doi:10.1021/1a904817f

120. Fortuna S, Colard Catheline AL, Troisi A, Bon Stefan AF (2009) Packing patterns of silica nanoparticles on surfaces of armored polystyrene latex particles. Langmuir ACS J surf colloids 25(21):12399-12403

121. Ma H, Dai LL (2009) Synthesis of polystyrene-silica composite particles via one-step nanoparticle-stabilized emulsion polymerization. J Colloid Interface Sci 333(2):807-811

122. Sheibat-Othman N, Bourgeat-Lami E (2009) Use of silica particles for the formation of organic-inorganic particles by surfactant-free emulsion polymerization. Langmuir 25(17):10121-10133

123. Bon Stefan AF, Colver Patrick J (2007) Pickering miniemulsion polymerization using Laponite clay as a stabilizer. Langmuir 23(16):8316-8322

124. Yu C-L, Kang J-S, Zhang F-A (2009) The effect of nano-SiO ${ }_{2}$ colloid on soap-free emulsion polymerization of methyl methacrylate and hydroxyethyl methacrylate. J Macromol Sci A Pure Appl Chem 46(9):870-875

125. Song X, Yin G, Zhao Y, Wang H, Du Q (2009) Effect of an anionic monomer on the Pickering emulsion polymerization stabilized by titania hydrosol. J Polym Sci A Polym Chem 47(21):5728-5736

126. Song X, Zhao Y, Wang H, Du Q (2009) Fabrication of polymer microspheres using titania as a photocatalyst and Pickering stabilizer. Langmuir 25(8):4443-4449

127. Manoharan VN, Elsesser MT, Pine DJ (2003) Dense packing and symmetry in small clusters of microspheres. Science 301(5632):483-487 
128. Cho Y-S, Yi G-R, Lim J-M, Kim S-H, Manoharan Vinothan N, Pine David J, Yang S-M (2005) Self-organization of bidisperse colloids in water droplets. J Am Chem Soc 127(45):15968-15975

129. Cho Y-S, Yi G-R, Kim S-H, Jeon S-J, Elsesser MT, Yu HK, Yang S-M, Pine DJ (2007) Particles with coordinated patches or windows from oil-in-water emulsions. Chem Mater 19(13):3183-3193

130. Lee D, Weitz DA (2008) Double emulsion-templated nanoparticle colloidosomes with selective permeability. Adv Mater 20(18):3498-3503

131. Dinsmore AD, Hsu Ming F, Nikolaides MG, Marquez M, Bausch AR, Weitz DA (2002) Colloidosomes: selectively permeable capsules composed of colloidal particles. Science 298(5595):1006-1009

132. Jerri HA, Dutter RA, Velegol D (2009) Fabrication of stable anisotropic microcapsules. Soft Matter 5(4):827-834

133. Chaturvedi N, Jerri H, Velegol D (2008) Design and characterization of randomly speckled spheres. Langmuir 24(14):7618-7622

134. Yake AM, Snyder CE, Velegol D (2007) Site-specific functionalization on individual colloids: size control, stability, and multilayers. Langmuir 23(17):9069-9075

135. Snyder CE, Yake AM, Feick JD, Velegol D (2005) Nanoscale functionalization and sitespecific assembly of colloids by particle lithography. Langmuir 21(11):4813-4815

136. Xia Y, Yin Y, Lu Y, McLennan J (2003) Template-assisted self-assembly of spherical colloids into complex and controllable structures. Adv Funct Mater 13(12):907-918 